\title{
The Value of Health and Longevity
}

\section{Kevin M. Murphy and Robert H. Topel}

University of Chicago and National Bureau of Economic Research

We develop a framework for valuing improvements in health and apply it to past and prospective reductions in mortality in the United States. We calculate social values of (i) increased longevity over the twentieth century, (ii) progress against various diseases after 1970, and (iii) potential future progress against major diseases. Cumulative gains in life expectancy after 1900 were worth over $\$ 1.2$ million to the representative American in 2000, whereas post-1970 gains added about $\$ 3.2$ trillion per year to national wealth, equal to about half of GDP. Potential gains from future health improvements are also large; for example, a 1 percent reduction in cancer mortality would be worth $\$ 500$ billion.

\section{Introduction}

During the twentieth century life expectancy at birth for a representative American increased by roughly 30 years. In 1900, nearly 18 percent of males born in the United States died before their first birthday; today, cumulative mortality does not reach 18 percent until age 62. ${ }^{1}$ This re-

The authors are also research associates of the George J. Stigler Center for the Study of the Economy and the State. We acknowledge support from the Milken Foundation and Lasker Charitable Trust. We received valuable comments from many colleagues, from two anonymous referees, and from the editor. An earlier version was presented as keynote lectures to the European meetings of the Econometric Society and the Society of Labor Economists, as the Thompson Lecture to the Midwest Economic Association, the Pihl Lecture at Wayne State University, and in workshops at Massachusetts Institute of Technology, Yale, Chicago, Stanford, Texas A\&M, Wisconsin, NBER, and Uppsala.

${ }^{1}$ Death rates by age are recorded in Vital Statistics of the United States. Longer-term data are scant but suggest that progress accelerated up until about 1950 . Swedish data since 1751 show an increase in life expectancy of six years between 1800 and 1850, nine years between 1850 and 1900, 17 years between 1900 and 1950, and nine years between 1950 and 2000 (Statistics Sweden, Program for Population Statistics). 
markable increase in longevity reflects progress against a variety of afflictions, driving reductions in mortality at all ages. It illustrates a substantial, but unmeasured, increase in social welfare due to improved health.

This paper develops and applies an economic framework for valuing improvements in health, based on individuals' willingness to pay. We estimate the economic gains from declining mortality in the United States over the twentieth century, and we value the prospective gains that could be obtained from further progress against major diseases. These values are enormous. Gains in life expectancy over the century were worth over $\$ 1.2$ million per person to the current population. From 1970 to 2000 , gains in life expectancy added about $\$ 3.2$ trillion per year to national wealth, with half of these gains due to progress against heart disease alone. Looking ahead, we estimate that even modest progress against major diseases would be extremely valuable. For example, a permanent 1 percent reduction in mortality from cancer has a present value to current and future generations of Americans of nearly $\$ 500$ billion, whereas a cure (if one is feasible) would be worth about $\$ 50$ trillion.

Our analysis of the value of health improvements is founded on individuals' maximization of lifetime expected utility. We distinguish two types of health improvements: those that extend life and those that raise the quality of life. Life extension is valued because utility from goods and leisure is enjoyed longer, and improvements in the quality of life raise utility from given amounts of goods and leisure. This framework delivers precise expressions for the value of a life-year, for the value of remaining life, and for changes in these values when health improves. We show that the social value of improvements in health is greater $(a)$ the larger the population, $(b)$ the higher lifetime incomes, $(c)$ the greater the existing level of health, and $(d)$ the closer the ages in the population to the age of onset of disease. These factors underlie a rising valuation of health improvements over the twentieth century and into the future. As the population grows, as incomes grow, as health levels improve, and as the baby-boom generation approaches the primary ages of disease-related death, the social value of improvements in health will continue to rise.

We also show that improvements in health tend to be complementary; for example, improvements in life expectancy raise willingness to pay for further health improvements by increasing the value of remaining life. This means that advances against one disease, say heart disease, raise the value of progress against other age-related ailments such as cancer or Alzheimer's. This is of significant empirical relevance: we find that reductions in mortality since 1970 have raised the value of further health progress by about 18 percent. 
An analysis of the value of health improvements is a first step toward evaluating the social returns to medical research and health-augmenting innovations. Improvements in health are partially determined by society's stock of medical knowledge, for which basic medical research is a key input. The United States invests about $\$ 60$ billion annually in medical research, of which about 40 percent is federally funded, accounting for 25 percent of government research and development outlays. ${ }^{2}$ The $\$ 27$ billion federal expenditure for health-related research in fiscal year 2003 represented a real dollar doubling over 1993 outlays. Are these expenditures warranted? Our analysis suggests that the returns to basic research may be quite large, so that substantially greater expenditures may be worthwhile. For example, take our estimate that a 1 percent reduction in cancer mortality would be worth about $\$ 500$ billion. Then a "war on cancer" that would spend an additional $\$ 100$ billion on cancer research and treatment would be worthwhile if it has a one in five chance of reducing mortality by 1 percent and a four in five chance of doing nothing at all.

Our analysis highlights some of the important economic issues surrounding the valuation of improvements in health, health research, and the growth in health expenditures. Many of these issues have significant policy implications. For example, the annuitization of many public and private retirement benefits (Social Security, private pensions, Medicare, and private medical insurance) and the prevalence of third-party payers increase incentives to spend on medical care, even when benefits are far smaller than costs. These distortions also skew investments in research away from cost-decreasing improvements in technology since the demand for care is artificially price insensitive. This creates "secondbest" considerations in valuing medical advances: innovations that would otherwise be welfare improving may be socially wasteful because ex post utilization decisions are distorted. Then a correct valuation of health advances must account for the induced effect on future costs. Our methodology does this, and we provide evidence on the value of improving health relative to increased health care expenditures since 1970. Even ignoring health-induced changes in the quality of life, we find that the aggregate value of increased longevity since 1970 has greatly exceeded additional costs of health care. In some groups, however, especially elderly women, we find that additional costs exceed that value of life-years gained.

\footnotetext{
${ }^{2}$ The distribution of health R\&D expenditure is reported by the National Institutes of Health (http://www.cdc.gov/nchs/products/pubs/pubd/hus/tables/2001/01hus126 .pdf). Pharmaceutical industry R\&D expenditures are reported in http://www.phrma.org/ publications/publications/profile02/chapter2.pdf. Government expenditures for health R\&D are reported by the National Science Foundation (http://www.nsf.gov/sbe/srs/ nsf02330/historic.htm).
} 


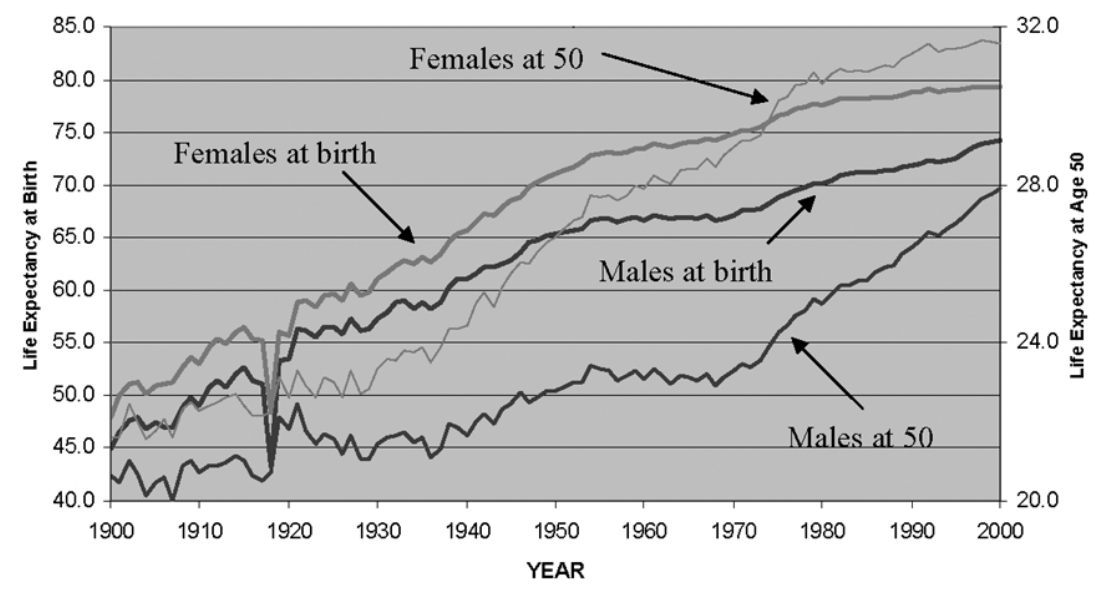

Fig. 1.-Life expectancy at birth and age 50, United States, 1900-2000

\section{The Setting: Long-Term Evidence of Improvements in Health}

Figure 1 shows life expectancy at birth and age 50 in the United States since 1900. These and other estimates that follow are based on crosssectional age-specific death rates at each date, so (when health is improving) they will underestimate life expectancy for a given birth cohort. The figure shows that life expectancy over the century increased by about 30 years. Progress during the first half of the century was rapid and concentrated at younger ages: remaining life expectancy at age 50 grew only slightly. Progress slowed between 1950 and 1970, especially for men, but the upward trend began again after 1970. Late-century gains were especially prominent for older individuals: expected remaining life of 50-year-old men has increased by over five years since $1970 .^{3}$

This shift in the age distribution of rising longevity reflects differential progress against life-threatening ailments, shown in table 1 . Since 1950 the largest single contributor is reduced mortality from heart disease, which added more than 3.5 years to the expected lifetimes of both men and women. When combined with progress against strokes, progress against cardiovascular diseases added 4.7 and 5.1 years to the expected lifetimes of men and women, with most of the gain occurring after 1970.

These data are well known to demographers and health researchers, but their implications for economic well-being have not been widely

\footnotetext{
${ }^{3}$ Evidence for other developed countries is similar. For OECD countries, from 1960 to 2000 the average at-birth life expectancy of women increased by nine years and that of men by eight years. See OECD Health Data, table 1, Life Expectancy in Years (http:// www.oecd.org/xls/M00031000/M00031357.xls).
} 
TABLE 1

Additional Life-Years Due to Reduced Mortality from Selected Causes, by DECADE, 1950-2000

\begin{tabular}{|c|c|c|c|c|c|c|}
\hline Disease & $1950-60$ & $1960-70$ & $1970-80$ & $1980-90$ & $1990-2000$ & Total \\
\hline & \multicolumn{6}{|c|}{ Men } \\
\hline Infant mortality & .54 & .36 & .75 & .23 & .20 & 2.07 \\
\hline Heart disease & .16 & .38 & 1.05 & 1.26 & .88 & 3.73 \\
\hline Cancer & -.19 & -.17 & -.08 & .02 & .43 & .01 \\
\hline Stroke & .10 & .15 & .41 & .24 & .08 & .98 \\
\hline Accidents & .18 & -.15 & .37 & .41 & .17 & .98 \\
\hline Other & .54 & -.19 & .41 & -.31 & .85 & 1.30 \\
\hline \multirow[t]{2}{*}{ Total } & 1.33 & .37 & 2.92 & 1.85 & 2.60 & 9.07 \\
\hline & \multicolumn{6}{|c|}{ Women } \\
\hline Infant mortality & .40 & .35 & .59 & .22 & .13 & 1.68 \\
\hline Heart disease & .59 & .72 & .87 & .90 & .46 & 3.54 \\
\hline Cancer & .20 & .07 & -.01 & -.11 & .17 & .31 \\
\hline Stroke & .20 & .33 & .63 & .38 & .06 & 1.59 \\
\hline Accidents & .10 & -.04 & .17 & .13 & .01 & .36 \\
\hline Other & .77 & .19 & .69 & -.25 & -.04 & 1.36 \\
\hline Total & 2.25 & 1.61 & 2.94 & 1.25 & .79 & 8.85 \\
\hline
\end{tabular}

Source.-Authors' calculations from Centers for Disease Control, Vital Statistics, Special Reports, various years.

NoтE.-Figures are additional expected life-years calculated from cross-sectional age-specific mortality rates in each year. Entries for each cause of death are contributions to additional expected life-years over the decade due to changes in mortality rates from that cause.

studied. ${ }^{4}$ Health improvements are a form of economic progress, and their valuation is important for two reasons. First, traditional measures of economic growth and welfare, based on national income accounts, make no attempt to account for this source of rising living standards. They do not count the value to the existing population either of living longer or of living "better." They therefore underestimate increases in well-being when health is improving. Second, public expenditure accounts for a large portion of both medical research and the provision of medical care. Efficient decisions require a framework for measuring the value of treatment and of research-based medical progress.

\section{Economic Framework: Valuing Improvements in Health}

Advances in health-related knowledge affect the quality of life and the risks of mortality over the life cycle. We assume that these effects are channeled through the intangible "health" of individuals, of which we distinguish two types. The first, $H(t)$, raises the quality of life without

\footnotetext{
${ }^{4}$ Related literature includes the papers collected in Measuring the Gains from Medical Research: An Economic Approach (2003), especially chapters by Murphy and Topel (2003) and Nordhaus (2003). The study by Usher (1973) is an early attempt to include health in national income accounts, and Arthur (1981), Rosen (1988, 1994), and Ehrlich and Chuma (1990) develop frameworks for valuing life extension.
} 
affecting mortality. For example, technologies that improve mental health or reduce the effects of arthritis may increase instantaneous utility without affecting longevity. The other, $G(t)$, affects mortality without affecting the quality of life. New methods of detecting treatable diseases or advances in surgical techniques are examples. Many advances affect both types of health, for example, medicines that reduce blood pressure or retard the advance of cancer. The types $H(t)$ and $G(t)$ are also affected by environmental factors, the state of health technologies, and individuals' choices. We relegate these choices to the background, so health is determined outside the model.

We build on the life expectancy analyses of Arthur (1981) and Rosen $(1988,1994)$ by assuming that willingness to pay for health is determined by maximization of lifetime utility. Remaining lifetime expected utility for an individual of age $a$ is

$$
\int_{a}^{\infty} H(t) u(c(t), l(t)) \tilde{S}(t, a) e^{-\rho(t-a)} d t
$$

where $\rho$ is the rate of time preference, and we have normalized the utility of death at zero. The term $H(t)$ enters multiplicatively in (1), so we assume that type $H$ health enhances the "quality" of life by increasing utility from consumption, $c(t)$, and nonmarket time, $l(t) .{ }^{5}$ Type $G$ health enters through the survivor function:

$$
\tilde{S}(t, a)=\exp \left[-\int_{a}^{t} \lambda(\tau, G(\tau)) d \tau\right]
$$

where $\lambda(\tau, G(\tau))$ is the instantaneous mortality (hazard) rate, and $\tilde{S}(t$, $a$ ) is the probability of survival from age $a$ to $t$. We assume $\lambda_{G}^{\prime}<0$ : greater type $G$ health reduces mortality. Then for any factor $\alpha$ that affects mortality, the impact on $\tilde{S}(t, a)$ is

$$
\tilde{S}_{\alpha}^{\prime}(t, a)=-\tilde{S}(t, a) \int_{a}^{t} \lambda_{\alpha}^{\prime}(\tau, G(\tau)) d \tau=\tilde{S}(t, a) \Gamma_{\alpha}(t, a) .
$$

A given change in the hazard at some age prior to $t$ has a larger impact on $\tilde{S}(t, a)$ when $\tilde{S}(t, a)$ is itself large. This property has important implications for valuing health improvements, which we discuss below.

\footnotetext{
${ }^{5}$ This assumption has several important implications explored below. It is consistent with methods for evaluating the quality of life for persons with various ailments. The most popular asks individuals to index their quality of a life-year against "perfect" health. The resulting quality-adjusted life-years give values of $H \leq 1$, where $H=1$ indexes perfect health.
} 
Assume a perfect annuity market, so the expected discounted value of future consumption equals expected wealth:

$$
A(a)+\int_{a}^{\infty}[y(t)-c(t)] \tilde{S}(t, a) e^{-r(t-a)} d t=0
$$

where $r$ is the interest rate, $A(a)$ is initial assets, and $y(t)$ is life-contingent income. With endogenous labor supply, $y(t)=w(t)[1-l(t)]+b(t)$, where $w(t)$ is the wage and $b(t)$ is life-contingent nonwage income such as social security or defined-benefit pension receipts.

The individual chooses $c(t)$ and $l(t)$ to maximize (1) subject to (4):

$$
\begin{aligned}
U(a)= & \int_{a}^{\infty}\left\{H(t) u(c(t), l(t)) e^{-\rho(t-a)}+\mu[y(t)-c(t)] e^{-r(t-a)}\right\} \tilde{S}(t, a) d t \\
& +\mu A(a) .
\end{aligned}
$$

Optimization yields the necessary conditions: ${ }^{6}$

$$
\begin{aligned}
& H(t) u_{c}^{\prime}(c(t), l(t))=\mu e^{-(r-\rho)(t-a)}, \\
& H(t) u_{l}^{\prime}(c(t), l(t))=w(t) \mu e^{-(r-\rho)(t-a)} .
\end{aligned}
$$

Notice that $H(t)$ and consumption of other goods are natural complements in our setup. For example, if type $H$ health declines at older ages, then consumption will also fall. ${ }^{7}$ This is consistent with evidence from studies of life cycle consumption, and we exploit this feature below in calibrating the value of a life-year.

Equation (5) is our basic building block for valuing health improvements, and it provides a monetary expression for the "value of life." Consider a small change $d \lambda(a)$ in the instantaneous hazard rate. From $(2), d \lambda(a)<0$ increases survivorship at all subsequent ages. The impact on expected lifetime utility is

$$
d U(a)=-d \lambda(a) \int_{a}^{\infty}\left\{H(t) u(c(t), l(t)) e^{-\rho(t-a)}+\mu[y(t)-c(t)] e^{-r(t-a)}\right\} \tilde{S}(t) d t .
$$

\footnotetext{
${ }^{6}$ We have ignored personal medical expenditures, which might be treated as a nonconsumption expense. We return to a consideration of medical expenditures and the costs of health care in our empirical work.

${ }^{7} \mathrm{~A}$ sufficient condition is $u_{c l}(c, l) \geq 0$. If $u_{c l}<0$, consumption can rise with $H$.
} 
The value of life at $a$ is the marginal rate of substitution between $\lambda(a)$ and assets, $A(a)$ :

$$
\begin{aligned}
V_{\lambda}(a) & \equiv-\frac{\partial U(a) / \partial \lambda(a)}{\partial U(a) / \partial A(a)} \\
& =\frac{1}{\mu} \int_{a}^{\infty}\left\{H(t) u(c(t), l(t)) e^{-\rho(t-a)}+\mu[y(t)-c(t)] e^{-r(t-a)}\right\} \tilde{S}(t) d t .
\end{aligned}
$$

From (6), the value of life at age $a$ is

$$
V_{\lambda}(a)=\int_{a}^{\infty} v(t) e^{-r(t-a)} \tilde{S}(t, a) d t
$$

where

$$
v(t)=\frac{u(c(t), l(t))}{u_{c}^{\prime}}-c(t)+y(t)
$$

is the "value of a life-year"-the value of utility and net savings at age $t$. $^{8}$ Savings affect $v(t)$ because they finance consumption in other periods, with marginal utility $\mu$. Note that the rate of time preference, $\rho$, does not appear in (7): the ability to borrow and lend causes future life-years to be discounted at the rate of interest. As both interest and mortality contribute to discounting the future, we define $S(t, a) \equiv e^{-r(t-a)} \tilde{S}(t, a)$.

The term $H(t)$ does not appear explicitly in the value of life formula (7) because we assumed that type $H$ health raises total utility and the marginal utility of consumption by the same proportional amount. So $H$ is valuable, as we will see, yet willingness to pay for additional lifeyears does not depend on $H$. For example, suppose that a physical limitation such as partial paralysis reduces a person's $H$ by a uniform proportion at all ages. Then (7) and (8) imply that her value of life is the same as for an otherwise identical individual without such a limitation, though she would of course still pay to eliminate her physical limitation. This property accords with empirical evidence, as summarized by the U.S. Environmental Protection Agency's Science Advisory Board (2000): "There are no published studies that show that persons with physical limitations or chronic illnesses are willing to pay less to increase their longevity than persons without those limitations. People with physical limitations appear to adjust to their conditions, and their

\footnotetext{
${ }^{8}$ Rosen (1988) gets a similar expression for the value of longevity in a model without saving or nonmarket time. Topel and Welch (1986) derive the effect of saving on instantaneous utility.
} 
willingness to pay to reduce fatal risks is therefore not affected" (http://www.epa.gov/sab/pdf/eeacf013.pdf). ${ }^{9}$

\section{Life Cycle Changes in the Value of Life}

While different levels of $H$ between individuals do not affect the values of life or of life-years, relative levels of $H(t)$ within a lifetime do affect relative values of life-years. The rate of change in the value of a life-year as a person ages is

$$
\begin{aligned}
\dot{v}(t)= & \frac{y(t)}{v(t)}\left\{s_{w}(t) \dot{w}(t)+\left[1-s_{w}(t)\right] \dot{b}(t)\right\} \\
& +\left[1-\frac{y(t)-c(t)}{v(t)}\right][\dot{H}(t)+r-\rho],
\end{aligned}
$$

where $s_{w}$ is the share of earnings in life-contingent income. The first term in (9) ties the age profile of $v(t)$ to changes in income. Before retirement, we can set $s_{w}=1$, so $v(t)$ tracks wages; indexing of postretirement annuities suggests $\dot{b}=0$. The second term ties $v(t)$ to the life cycle shape of $H(t)$ : life-years become less valuable as health deteriorates, and persons in declining health are more impatient. This again follows from complementarity: within a lifetime, planned consumption is low when health is expected to be poor, so $v(t)$ is also low.

Estimates of the value of a statistical life (VSL) typically assume that VSLs do not depend on age: it is just as valuable to "save" a 60-year-old as a 40-year-old. In our framework, $V_{\lambda}(a)$ follows the usual law of motion for an asset price:

$$
\frac{\partial V_{\lambda}(a)}{\partial a}=[r+\lambda(a)] V_{\lambda}(a)-v(a) .
$$

When $R(a)$ represents the (discounted) length of remaining life at age $a$, this becomes

$$
\frac{\partial V_{\lambda}(a)}{\partial a}=[r+\lambda(a)] \int_{a}^{\infty}[v(t)-v(a)] S(t, a) d t+v(a) \frac{\partial R(a)}{\partial a} .
$$

Life tables for developed economies indicate that the last term is negative at all ages. From (9) the first term will be positive at younger ages because wages rise with age and $H$ is unlikely to deteriorate much among the young. Later in life, $V_{\lambda}(a)$ declines because wage growth is negligible, $H$ deteriorates, and $R(a)$ is falling.

\footnotetext{
${ }^{9}$ Other forms of specifying the utility from $H$ would not deliver this property. For example, if $H$ is additive, willingness to pay for longevity rises with $H$.
} 
Willingness to Pay for Improvements in Health

Consider some factor, $\alpha$, that can affect both type $H$ and type $G$ health. We can think of $\alpha$ as the state of "medical knowledge"-techniques, medicines, and so on-though it can equally represent environmental improvements, improved nutrition, or access to medical care. The value of a medical advance follows from displacement of (5):

$$
\begin{aligned}
V_{\alpha}(a) & \equiv \frac{U_{\alpha}^{\prime}(a)}{\mu} \\
& =\int_{a}^{\infty} v(t) S(t, a) \Gamma_{\alpha}(t, a) d t+\int_{a}^{\infty} \frac{H_{\alpha}^{\prime}(t)}{H(t)} \frac{u(c(t), l(t))}{u_{c}} S(t, a) d t .
\end{aligned}
$$

Equation (11) measures willingness to pay for any factor that affects health. The first term is the value of additional lifetime utility from changes in mortality, where $S(t, a) \Gamma_{\alpha}(t, a)=S_{\alpha}(t, a)$. The second term is the value of changes in type $H$ health. If savings are negligible, proportional changes in $H$ and in the survivor function are valued in the same way. Then living a bit better is like living a bit longer.

Equation (11) is our tool for valuing past and prospective changes in health. To make empirical headway, we restrict utility to be homothetic. So $u(c, l) \equiv u(z(c, l))$, where $z$ is linear homogeneous. Then the value of a life-year is

$$
v=y+\frac{u(c, l)}{u_{c}(c, l)}-c=y+\frac{u\left(z_{c} c+z_{l} l\right)}{z_{c} u^{\prime}(z)}-c,
$$

so $z$ is a composite good that aggregates consumption and leisure. Define full consumption and full income by adding the shadow value of nonmarket time to each:

$$
\begin{aligned}
& c^{F}=c+\frac{z_{l}}{z_{c}} l=z_{c}^{-1} z, \\
& y^{F}=y+\frac{z_{l}}{z_{c}} l,
\end{aligned}
$$

where for labor force participants we know that

$$
\frac{u_{l}(z)}{u_{c}(z)}=\frac{z_{l}}{z_{c}}=w,
$$

the wage. Then

$$
v=y+\frac{u\left(z_{c} c+z_{l} l\right)}{z_{c} u^{\prime}(z)}-c=y^{F}+c^{F}\left[\frac{u(z)}{z u^{\prime}(z)}-1\right]
$$


and

$$
v=y^{F}+c^{F} \Phi(z),
$$

where $\Phi(z)$ is consumer surplus per unit of $z$, or surplus per dollar of full consumption. It is positive when average utility of $z$ exceeds marginal utility. We do not require $\Phi(z) \geq 0$, however. Positive utility may require composite consumption above some subsistence level, $z_{0}$, where $u\left(z_{0}\right)=0$. Then $\Phi\left(z_{0}\right)=-1$, and there is a $z_{1}>z_{0}$ where $\Phi\left(z_{1}\right)=0 .{ }^{10}$

Equation (13) demonstrates two important points about the value of a life-year. First, even if $\Phi(z)=0$, the value of being alive exceeds measured income because of the value of nonmarket time. This is especially important for persons without wage and salary income-such as the retired-for whom the value of nonmarket time accounts for most of $y^{F}$. Preretirement, nonworking hours are valued at $w$, and annual hours of leisure are (reasonably) greater than hours worked; so $y^{F}$ may be more than double earned income. Second, full consumption adds to this value if $\Phi(z)>0$. For example, if $\Phi(z)=1$ (surplus equals consumption expenditure) and $y=c$ (no savings), the value of a life-year is over four times annual income. For a typical male at peak life cycle earnings—roughly $\$ 45,000$ per year-this puts $v(t)$ above $\$ 180,000$.

Now use (13) to rewrite (7) and (11):

$$
V_{\lambda}(a)=\int_{a}^{\infty}\left[y^{F}(t)+c^{F}(t) \Phi(z(t))\right] S(t, a) d t
$$

and

$$
\begin{aligned}
V_{\alpha}(a)= & \int_{a}^{\infty}\left[y^{F}(t)+c^{F}(t) \Phi(z(t))\right] S(t, a) \Gamma_{\alpha}(t, a) d t \\
& +\int_{a}^{\infty} \frac{H_{\alpha}^{\prime}(t)}{H(t)} c^{F}(t)[1+\Phi(z(t))] S(t, a) d t .
\end{aligned}
$$

Equation (14) is the value of an age $a$ statistical life-the expected discounted value of full income and surplus on full consumption. Equation (15) is the age $a$ willingness to pay for improving health. Both are proportional to full income and consumption, so health is perhaps the ultimate "normal" good. To pursue this point, let $\sigma(z)=-u^{\prime}(z) / z u^{\prime \prime}(z)$ be the elasticity of intertemporal substitution, and consider the impact

\footnotetext{
${ }^{10}$ Rosen (1988) uses this property in a one-period model, emphasizing the convexity introduced by $z_{0}$ and its implications for risk taking. In a multiperiod setting, $v(t)<0$ does not mean that death is preferred, since the value of continued life at $a$ is determined by $V_{\lambda}(a)$, which will be positive if future prospects are brighter.
} 
of increased income on $v(t)$. When we abstract from saving by setting $y=c$, the income elasticity of $v$ is

$$
\frac{\partial \log v}{\partial \log y}=1+\frac{1}{\sigma(z)}-\frac{1}{1+\Phi(z)^{-1}},
$$

which exceeds 1.0 if $\sigma(z)<1+\Phi(z)^{-1}$. Later evidence indicates $\Phi(z) \approx$ 2 in middle age, and empirical studies suggest $\sigma(z) \leq 1.0$. Then the income elasticity of the value of a life-year exceeds 1.33 .

Inspection of (14)-(16) offers several implications for valuing health improvements:

- Willingness to pay for health rises with wealth, so growth is a boon to health-related investments. This is especially important when willingness to pay is income elastic, as suggested by (16). Then richer societies are likely to invest proportionally more. ${ }^{11}$

- The value of a life-year includes the value of nonmarket time. Common attempts to value life-years on the basis of income or consumption expenditures alone neglect much of what people value, especially when health improvements are concentrated at older ages, as has occurred in recent decades. ${ }^{12}$

- With wealth constant, health improvements are more valuable when surplus, $\Phi$, is large. This occurs when the demand for current consumption is inelastic, so consumption expenditures at different ages are poor substitutes: $\sigma(z)$ is small. Then loss of a year of life cannot be offset by simply reallocating consumption to other years. We exploit this notion in the next section, gauging $\Phi$ from evidence on intertemporal substitution in consumption.

- The value of progress against a disease is greatest when the current age, $a$, is close to, but before, the typical age of onset of the disease.

\section{Complementarity of Health Improvements: Increasing Returns}

Suppose that a medical advance reduces mortality from heart disease, so a 30-year-old is more likely to survive to age 60 . This increases the value of progress against cancer because the individual is more likely to be around to enjoy the benefits. Progress against cancer is not worth much if one is sure to die of a heart attack first.

This example suggests a form of increasing returns inherent to health:

${ }^{11}$ Whether health spending is income elastic depends on (16) as well as on the rate of diminishing returns in health production and in consumption. Hall and Jones (2005) provide a related discussion.

${ }^{12}$ For example, the Conference Board of Canada (2001) estimates the "costs" of excess mortality from what a decedent would have produced, not the value to the individual of remaining alive. 
past advances raise the value of further improvements. To formalize the point, assume two diseases, $A$ and $B$, that affect only mortality. By the nature of competing risks, $\lambda(t)=\lambda^{A}(t)+\lambda^{B}(t)$, where $\lambda^{j}(t)$ is the death rate from disease $j$. Let $d \alpha(d \beta)$ be an advance that reduces mortality from $A(B)$, so $\lambda_{\alpha}^{A}<0$. Differentiation of (15) yields ${ }^{13}$

$$
V_{\alpha \beta}(a) \equiv \frac{\partial V_{\alpha}(a)}{\partial \beta}=\int_{a}^{\infty}\left[y^{F}(t)+\Phi(z) c^{F}(t)\right] S(t, a) \Gamma_{\alpha}(t, a) \Gamma_{\beta}(t, a) d t>0 .
$$

The functions $\Gamma_{\alpha} \geq 0$ and $\Gamma_{\beta} \geq 0$ are derivatives of $\ln S(t, a)$; see (3). They are nondecreasing and strictly positive for some $t$, so (17) is positive. Progress against heart disease $(A)$ raises future values of $S(t, a)$. Then progress against cancer $(B)$ is more valuable because the individual is more likely to be alive when cancer threatens.

Equation (17) treats the case in which $A$ and $B$ affect mortality. If one or both ailments affect the quality of life, the effect will be channeled through the assumed complementarity of $H$ with consumption: a medical advance that raises $H(t)$ at some ages causes a reallocation of life cycle consumption, raising $v(t)$ at those ages as well. So suppose that $A$ affects mortality (cancer) but $B$ affects the quality of life in old age (Alzheimer's). By raising the value of life-years in old age, progress against Alzheimer's is complementary with advances that raise the probability of remaining alive. So mortality-reducing advances raise the value of type $\mathrm{H}$ health improvements that increase with age. Similarly, if both $A$ and $B$ affect the quality of life, they will be complementary if they raise $H$ at similar stages of life. So advances against arthritis and Alzheimer's are complementary because they both improve the lot of older people.

These complementarities in willingness to pay for health have important implications for private and social health expenditures. Improvements in health raise the value of further improvements. So the large health improvements of recent decades should increase the demand for health by individuals and also raise the social value of health infrastructure and research. We estimate this effect below.

\section{The Social Value of Improvements in Health}

An important application of our method is in assessing the value of medical advances or improvements in public health that increase society's "output" of health. These typically affect both current and future populations, so to measure their social value we must aggregate over the current and expected future populations that benefit. Individual willingness to pay is given by (15), so the social value of an advance

\footnotetext{
${ }^{13}$ We simplify and neglect wealth effects in this discussion; see Murphy and Topel $(2005 b)$.
} 
that improves health from date $\tau$ onward is

$$
W_{\alpha}(\tau)=\int_{a=0}^{\infty} N(a, \tau) V_{\alpha}(a) d a+N^{f}(\tau) V_{\alpha}(0)
$$

Here $N(a, \tau)$ is the population of age $a$ at date $\tau$ and $N^{f}(\tau)$ is the present value of future births. These enter the calculation because medical advances that improve health will also apply to future generations, for whom value is measured at birth. When combined with (15), (18) yields two additional implications:

- The current social value of a health advance is proportional to the size of the current and future populations to which it applies.

- Aggregate willingness to pay for progress against a disease will be highest when the age distribution of the population is concentrated near, but before, the typical age of onset of the disease. For example, the aging of the baby-boom generation has raised the social value of medical advances against age-related ailments.

In our empirical applications we will apply (18) in three ways. First, treating reductions in mortality at any past date $\tau$ as the outcome of technical improvements that increase health output, we will augment date $\tau$ national income to include the value of life-years "produced." Second, we use (18) to calculate what past reductions in mortality are worth today. For example, we calculate the current value of reductions in mortality from heart disease that occurred between 1970 and 2000. Third, we use (18) to calculate the prospective value of medical progress that would, say, reduce the average likelihood of dying from cancer or AIDS by some amount.

\section{Calibration: The Value of a Life-Year}

Our calibration strategy begins with estimates of the value of a statistical life. ${ }^{14}$ Empirical studies typically estimate the VSL from wage differences on jobs with varying probabilities of accidental death or from market prices for products that reduce the likelihood of fatal injury. Suppose that workers require a $\$ 500$ annual wage premium in order to accept a one in 10,000 greater annual probability of accidental death. Among 10,000 workers this would raise expected deaths by one each year, so the VSL is $\$ 500 \times \$ 10,000=\$ 5$ million. This is the conceptual equivalent of $V_{\lambda}(a)$ in (14). Viscusi's (1993) survey offers a "reasonable range" of \$4-\$9 million per statistical life, expressed in 2004 dollars, whereas Viscusi and Aldy (2003) suggest a narrower range of \$5.5-\$7.5 million.

\footnotetext{
${ }^{14}$ See Viscusi (1993) for a survey or Thaler and Rosen (1975) for an original analysis.
} 
Government agencies regularly update these estimates to account for economic growth and new methods and evidence; for example, the U.S. Environmental Protection Agency has used $\$ 6.3$ million in cost-benefit analyses since 1999 (see Dockins et al. [2004] for a review). As these values are derived from risk-income trade-offs for working-age individuals, we assume that the survivorship-weighted average of $V_{\lambda}(a)$ between ages 25 and 55 is $\$ 6.3$ million. Readers who prefer a different value may adjust things accordingly, since our estimates are scalable.

Given this value, it remains to impute a life cycle shape for $v(t)$. We construct $v(t)$ from the model's structure and empirical evidence on key parameters. Values of $y^{F}(t)$ can be constructed from life cycle wages, and paths of $c(t)$ and $c^{F}(t)$ follow

$$
\dot{c}=\sigma(r-\rho)+\sigma \dot{H}-(\eta-\sigma) s_{L} \dot{w}
$$

and

$$
\dot{c}^{F}=\sigma(r-\rho)+\sigma \dot{H}-(1-\sigma) s_{L} \dot{w},
$$

where $s_{L}$ is the share of leisure in $c^{F}(t)$ and $\eta$ is the elasticity of substitution between consumption and leisure in $z(c, l)$. Assume that $\sigma$ and $\eta$ are constants, so

$$
u(z)=\frac{z^{1-\sigma^{-1}}-z_{0}^{1-\sigma^{-1}}}{1-\sigma^{-1}} \Rightarrow \Phi(z)=\frac{1}{\sigma-1}\left[1-\sigma\left(\frac{z_{0}}{z}\right)^{1-\sigma^{-1}}\right] .
$$

The value of a life-year will be larger when demand for current full consumption is more inelastic, which occurs when $\sigma$ is small.

Many studies estimate $\sigma$ on the basis of versions of (19a). Most find that aggregate consumption growth is insensitive to the real interest rate, suggesting that $\sigma$ is close to zero. ${ }^{15}$ Then $\Phi(z)$ would be huge. Browning, Hansen, and Heckman (1999) survey estimates of $\sigma$ from micro data and conclude that $\sigma$ is "a bit" larger than 1.0. The ratio $z_{0} / z$ asks how much of current composite consumption individuals would sacrifice before they would rather be dead. We know of no formal evidence on this, though comparisons of living standards over time and across countries and individuals suggest that the ratio is quite small. Table 2 shows values of a life-year $v(t)$ under various assumptions on $\sigma$

${ }^{15}$ See Hansen and Singleton (1983), Hall (1988), and Campbell and Mankiw (1989). Barsky et al. (1997) use questionnaires to estimate an upper bound on $\sigma$ of 0.36 . Notice that $z_{0} / z$ must be sufficiently positive for values of $\sigma<1$ to generate positive surplus in (20). 
TABLE 2

Estimated Values of a Life-Year for 50-Year-Old Men

\begin{tabular}{lcccccc}
\hline \hline & \multicolumn{5}{c}{ Elasticity } & OF Intertemporal Substitution $(\sigma)$ \\
\cline { 2 - 7 }$z_{0} / z$ & 1.2 & 1.1 & 1.0 & .9 & .8 & .7 \\
\hline .05 & $\$ 282$ & $\$ 314$ & $\$ 360$ & $\$ 426$ & $\$ 535$ & $\$ 731$ \\
.10 & $\$ 229$ & $\$ 249$ & $\$ 276$ & $\$ 314$ & $\$ 373$ & $\$ 471$ \\
.20 & $\$ 169$ & $\$ 180$ & $\$ 193$ & $\$ 211$ & $\$ 237$ & $\$ 278$ \\
\hline
\end{tabular}

Note. - The table is based on the following equation:

$$
y^{F}=c^{F} \Phi(z)=y^{F}+c^{F} \frac{1}{\sigma-1}\left[1-\sigma\left(\frac{z_{0}}{z}\right)^{(\sigma-1) / \sigma}\right] .
$$

The table assumes a value of full consumption of $y^{F}=c^{F}=\$ 120,000$ for a 50 -year-old man with 4,000 total available hours per year and wages of $\$ 30 /$ hour, including benefits.

and $z_{0} / z$ for a 50 -year-old man who earns $\$ 60,000$ annually. ${ }^{16}$ We assume $y=c$, which is reasonable at this age. ${ }^{17}$ The implied values of $v(t)$ are large: when $\sigma=1.0$, the value of an age 50 life-year ranges from $\$ 193,000(\Phi=0.61)$ for $z_{0} / z=.2$ to $\$ 360,000(\Phi=2.0)$ for $z_{0} / z=$ .05 . For our calculations we assume $\sigma=.80$ at all ages and $z_{0} / z=.10$ at age 50, yielding $v(50)=\$ 373,000(\Phi=2.11)$.

To complete the calibration of $v(t)$, we choose parameters of (19) to fit empirical evidence on life cycle consumption and $y(t)$ to match life cycle wages. ${ }^{18}$ Empirical studies indicate that consumption peaks around age 50 and declines thereafter by about 2 percent annually. ${ }^{19}$ This is consistent with declining health after middle age and $r>\rho$, which we assume. Figure $2 a$ shows the shape of $H(t)$ implied by these studies and (19a): $H(t)$ is stable until age 40 but declines rapidly in late middle age. Given this profile for $H(t)$, figure $2 b$ shows profiles of $v(t), y^{F}(t)$, and $c^{F}(t)$ that yield an average VSL of $\$ 6.3$ million between ages 25 and $55 .{ }^{20}$

\footnotetext{
${ }^{16}$ Median annual earnings of men aged 45-54 who worked full-time in 1999 were about $\$ 45,000$ (http://www.census.gov/hhes/income/earnings/call1usmale.html). Nonwage benefits average about 29 percent of total compensation for a typical worker (http://www.bls.gov/news.release/ecec.t01.htm).

${ }^{17}$ In Consumer Expenditure Survey data for 2003, men aged 45-54 had average aftertax incomes of $\$ 53,195$ and consumption expenditures of $\$ 46,353$ (http://www.bls.gov/ cex/home.htm, table 29).

${ }^{18}$ For $y(t)$ we estimated a wage equation with a fourth-order polynomial in age.

${ }^{19}$ Fernandez-Villaverde and Krueger's (2004) relative consumption index peaks at 1.3 at age 50, then declines by about 2 percent annually. Banks, Blundell, and Tanner (1998) also find a peak at age 50, a subsequent rate of decline of 2 percent preretirement and about 1 percent postretirement. In our calibrations, relative consumption peaks at 1.29 at age 50, with a rate of decline of 2 percent at age 60 and 1.5-2 percent thereafter.

${ }^{20}$ We also assume that $r-\rho=.02, \eta=.50$, and retirement income replaces half of earnings from age 65.
} 
a

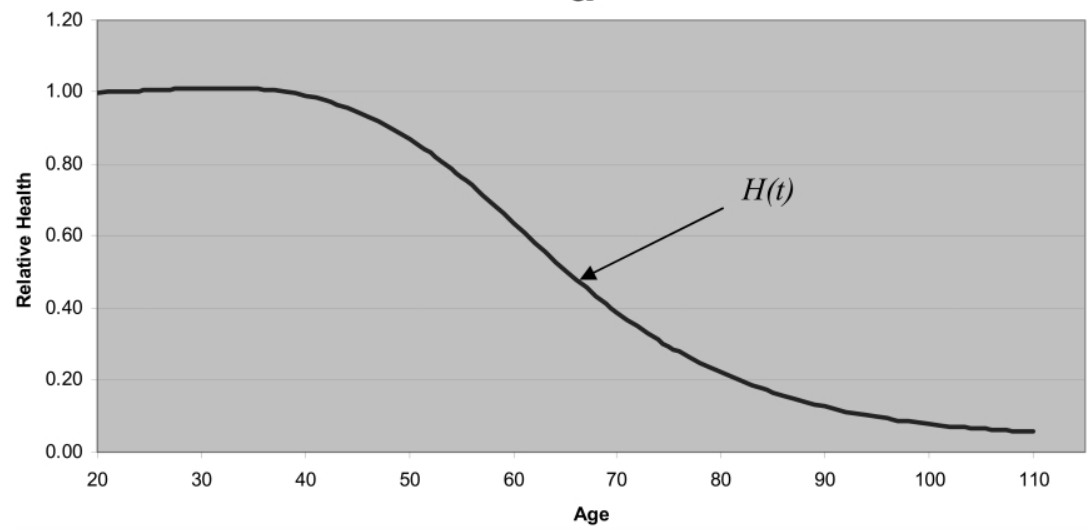

b

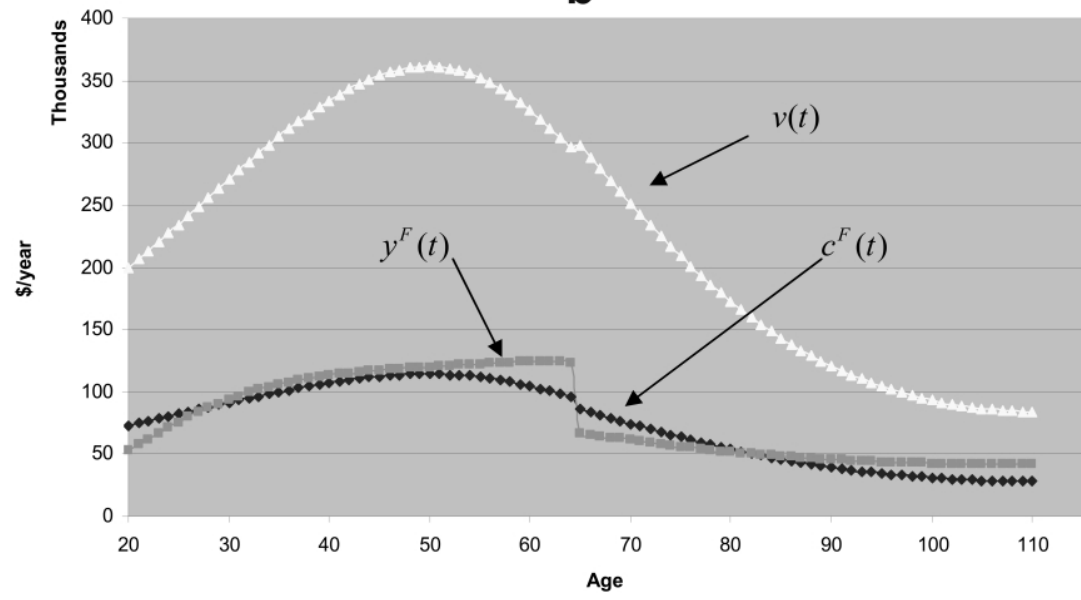

Fig. 2.- $a$, Implied shape of $H(t)$ consistent with consumption data. $b$, Life cycle profiles of full income, full consumption, and the value of a life-year.

The value of a life-year peaks at over $\$ 350,000$ around age 50 but falls by more than half by age 80 because consumption (health) declines. ${ }^{21}$

Figure 3 plots values of remaining life $V_{\lambda}(a)$ using $v(t)$ from figure

${ }^{21}$ Lichtenberg (2001) and Cutler and Richardson (1997) use \$25,000 per life-year saved in valuing gains from new drugs and advances against heart disease. This is less than income for a typical worker and certainly less than full income. Moore and Viscusi (1988) place the value of a life-year at $\$ 175,000$, and Miller, Calhoun, and Arthur (1990) find a value of $\$ 120,000$. None of these studies allow for age effects. See Tolley, Kenkel, and Fabian (1994) for a summary. 


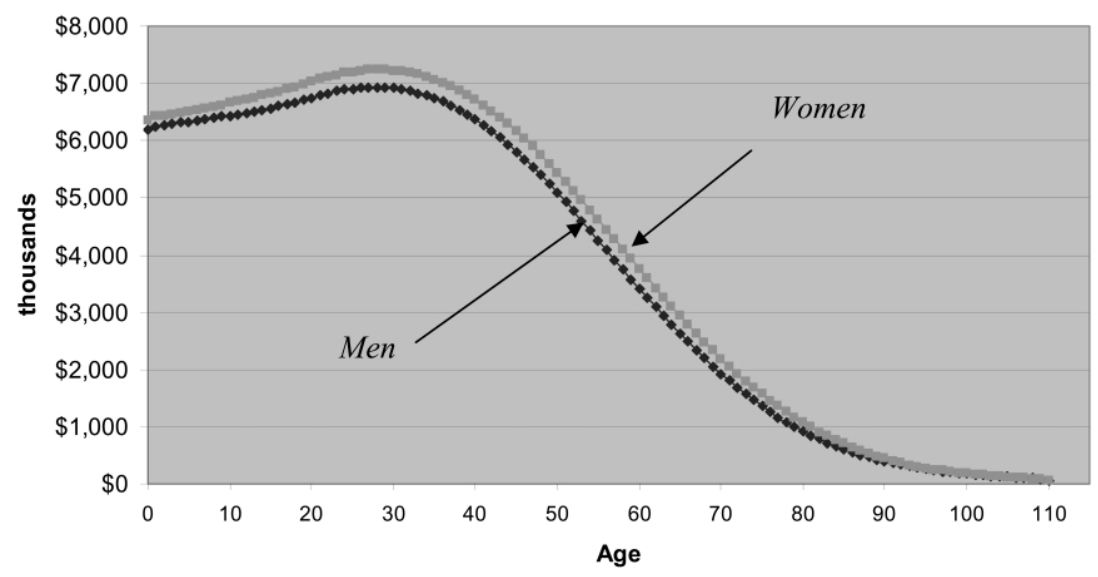

FIG. 3.-Value of remaining life ( $\$ 6.3$ million value of a statistical life)

$2 b .^{22}$ Women have higher values because we apply gender-specific survivor functions, and women live longer. The effects of discounting and future mortality are apparent: $V_{\lambda}(a)$ reaches $\$ 7$ million near age 30 and then falls, but figure $2 b$ showed that the value of a life-year rises until age 50. The value of $V_{\lambda}(a)$ declines to $\$ 5$ million at age 50 and $\$ 2$ million by age 70 .

\section{Estimating the Value of Past and Prospective Health Improvements}

This section measures long-term gains in health, the sources of those gains, and the prospective values of future progress against life-threatening diseases. We also account for changes in medical expenditures that accompany life-extending medical progress, which is a central feature of cost-benefit analyses of improving health care.

\section{Valuing Longevity Gains over the Twentieth Century}

Using mortality tables for the United States, figure 4 shows the timing and age distribution of increases in the value of life over the twentieth century. These are values received by individuals today from healthimproving advances achieved in the past. Vertical differences between two curves represent the present value of changes in survivor rates ac-

\footnotetext{
${ }^{22}$ For all the following calculations we value life-years for men and women equally, and years from birth to age 20 at their age 20 value.
} 
a

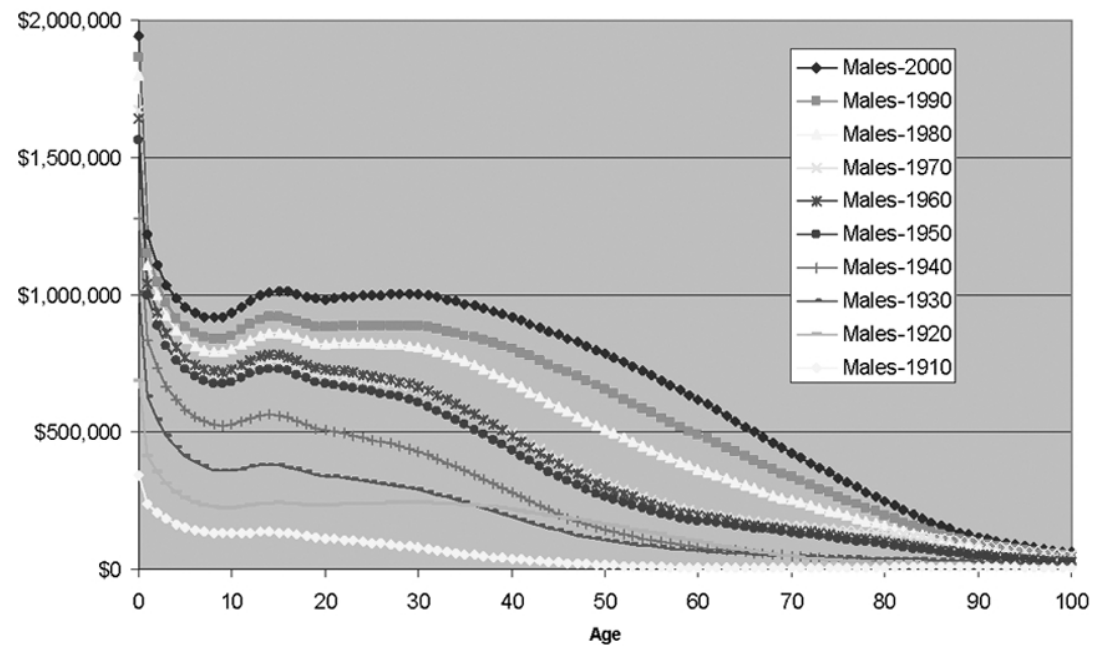

b

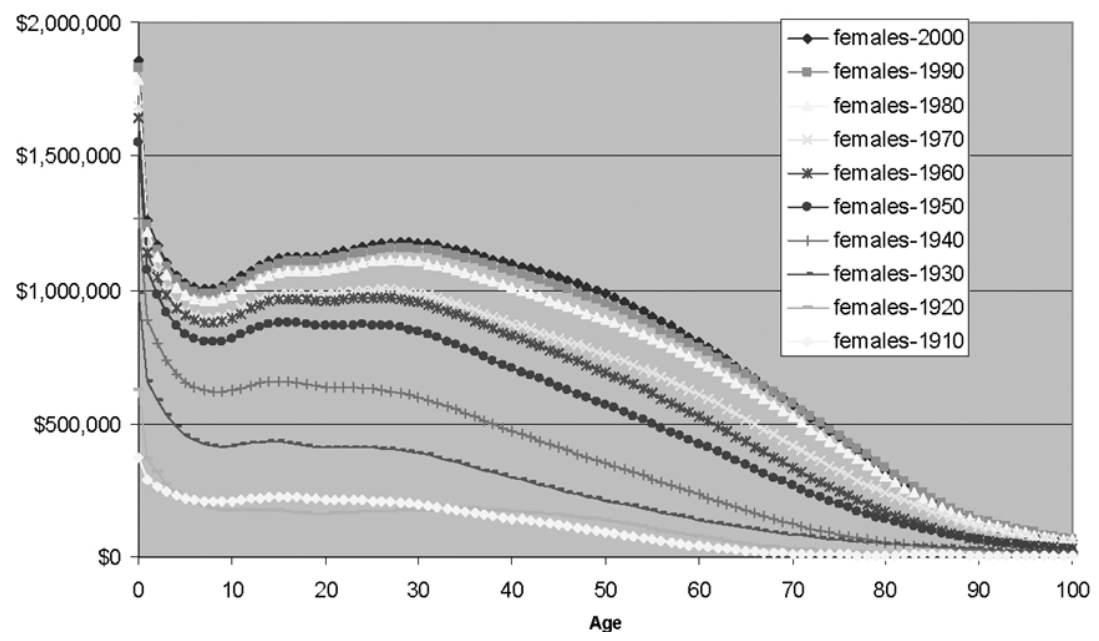

FIG. 4.-Cumulative values of longevity gains since 1900: $a$, men in 2000; $b$, women in 2000.

cruing to individuals of a particular age for a particular decade, so the top curve (2000) shows cumulative gains from 1900 to 2000, and so on.

The largest gains occur at birth and at young ages. Health advances over the twentieth century yielded additional life-years for a newborn with a present value of nearly $\$ 2$ million. Most of this occurred early: more than half occurred by 1930 and more than 80 percent by 1950 , 


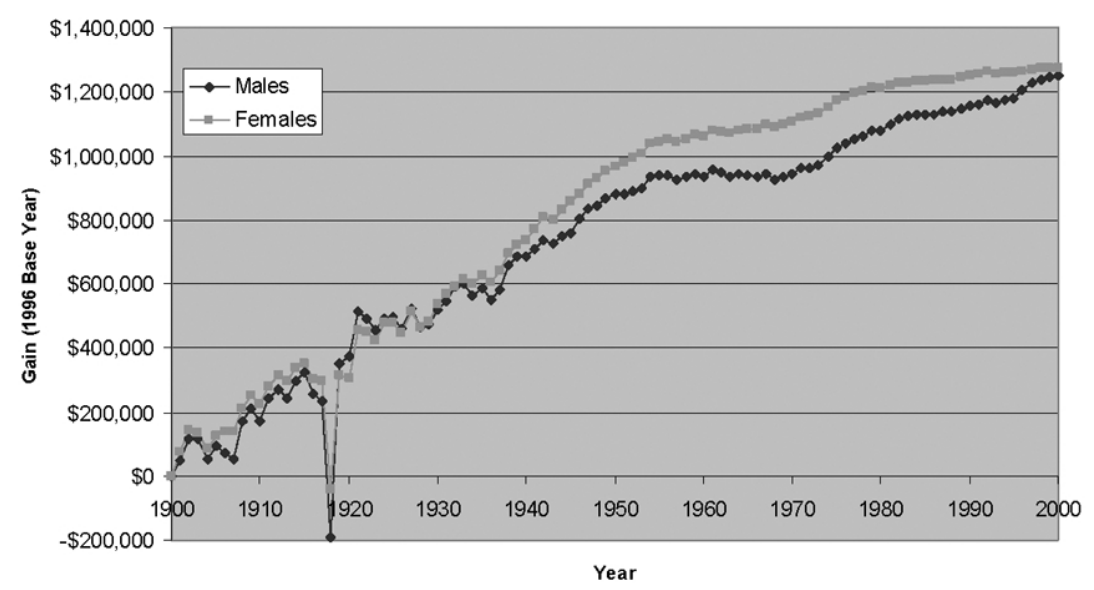

FIG. 5.-Population-weighted cumulative value of longevity gains since 1900

reflecting progress against infant mortality and childhood diseases. But gains are also very substantial for adults. Men aged 20-40 gained lifeyears worth roughly $\$ 1$ million. Women's gains were greater because we value life-years for men and women equally, but women gained more years. Notice that figure $4 b$ shows negligible progress for women after 1980, though men enjoyed substantial gains over this period (fig. $4 a$ ).

To evaluate whether these estimates are reasonable, consider the $\$ 1$ million gain enjoyed by a 30-year-old man. Over the century, the expected remaining duration of life for 30-year-old men increased by 11.3 years, from 34.9 to 46.2 . So think of a current 30 -year-old who is offered the choice of $(a)$ his current standard of living and health or $(b)$ a lump sum of $\$ 1$ million and the life expectancy of a 30-year-old in 1900, which is 11.3 years shorter. Our estimates imply that the choice is a close call, but for a payment of less than $\$ 1$ million he would keep his current health. For women, the corresponding gain in life expectancy is 14.9 years, from 36.4 to 50.5 , which is worth nearly $\$ 1.2$ million. ${ }^{23}$

Figure 5 further documents the difference in timing between men's and women's gains. We graph age-weighted average gains for men and women over the entire century, using end-of-century population weights. These cumulate to about $\$ 1.3$ million for the representative individual of each sex. Women's gains started to outpace men's in the 1930s, and progress for both men and women decelerated in the early 1950s, reflecting the near exhaustion of progress against infant and child mor-

${ }^{23}$ Nordhaus (2003) poses a related hypothetical question: if offered only one of post1950 gains in health or living standards, which would you choose? He estimates that gains in health and living standards after 1950 are of roughly equal value. 
tality. For men, health progress stalled for 20 years, and the female-male gap reached nearly $\$ 180,000$ by 1970 . Male progress resumed after 1970 , reflecting advances against adult ailments, and the gender disparity had vanished by the end of the century. ${ }^{24}$

Figures 4 and 5 value past gains at current willingness to pay, so they represent the current value of past progress: what people alive today gained from earlier improvements. An alternative is to value progress at the date it occurred, so newly "produced" life-years at date $\tau$ are a component of output-health capital - that will be enjoyed in future years and by future populations, but are uncounted in per capita national income. ${ }^{25}$ The result is an augmented measure of per capita income that counts the present value of reduced mortality at the date it is observed.

Table 3 reports the results. From 1900 to 1950 the per capita value of new life-years "produced" was roughly equal to output of goods and services. The decade 1910-20 is an exception because of the flu pandemic of 1917-19. Gains after 1950 form a smaller share of income because other forms of productivity grew faster. This accounting may also change one's perspective on relative growth rates from different decades: per capita GDP grew rapidly during the 1960s and slowly during the 1970s; yet production of health stagnated in the 1960s-the lowest in the century-but boomed in the 1970s.

\section{Post-1970 Gains}

We now turn to a more detailed examination of the post-1970 period, where mortality-reducing progress among adults accelerated. Figure 6 shows that the largest gains accrued to persons aged 40-60. Men enjoyed steady progress, with peak gains of $\$ 460,000$ for 50 -year-olds (who gained five years of life expectancy), about double the peak gains of women (2.8 years). Most of men's gain is due to progress against heart disease alone (fig. 7). This partly accounts for the late-century "convergence" between men and women, because women's progress stalled after 1980 (fig. 6b).

\footnotetext{
${ }^{24}$ Murphy and Topel (2005a) apply these methods to racial disparities in health, showing convergence in the value of health outcomes for blacks relative to whites.

${ }^{25}$ Nordhaus (2003) has a useful discussion of income accounting issues; see also Usher (1973). To value gains at date $\tau$, we use the shape of $v(t)$ in 2000 but rescale it by the ratio of gross domestic product per capita in years $\tau$ and 2000. We count reductions in mortality when they are observed, which may not be when they were produced. For example, improved neonatal care in year $\tau$ may reduce heart attacks in $\tau+50$. To obtain new health capital per capita, we include the value to future cohorts of a date $\tau$ reduction in mortality, as in (18), and divide by the date $\tau$ population. This "capital" approach is consistent with methods of national income accounting, where output is consumption plus the value of new capital.
} 
TABLE 3

Decade Averages of GDP and Production of Health Capital per Capita, 1900-2000 (2004 Dollars)

\begin{tabular}{|c|c|c|c|c|c|c|c|c|c|c|}
\hline & $1900-1910$ & 1910-20 & $1920-30$ & $1930-40$ & $1940-50$ & $1950-60$ & $1960-70$ & $1970-80$ & 1980-90 & $1990-2000$ \\
\hline GDP & $\$ 6,011$ & $\$ 7,239$ & $\$ 7,703$ & $\$ 7,578$ & $\$ 13,592$ & $\$ 15,856$ & $\$ 20,343$ & $\$ 25,342$ & $\$ 28,381$ & $\$ 32,057$ \\
\hline Health capital & $\$ 4,987$ & $\$ 2,754$ & $\$ 5,513$ & $\$ 6,062$ & $\$ 12,314$ & $\$ 4,951$ & $\$ 2,381$ & $\$ 12,839$ & $\$ 7,305$ & $\$ 8,240$ \\
\hline Total & $\$ 10,998$ & $\$ 9,993$ & $\$ 13,216$ & $\$ 13,640$ & $\$ 25,906$ & $\$ 20,807$ & $\$ 22,724$ & $\$ 38,181$ & $\$ 35,685$ & $\$ 40,297$ \\
\hline Share of health capital & .45 & .28 & .42 & .44 & .48 & .24 & .10 & .34 & .20 & .20 \\
\hline
\end{tabular}

SourcE. - Average annual real (2004 dollars) amounts. Authors' calculations for health capital. Values of GDP before 1929 are taken from Kuznets as compiled by Jones and Obstfeld (2001), downloaded from the NBER Web site (http://www.nber.org). Post-1929 data are taken from the U.S. Department of Commerce, Bureau of Economic Analysis. Pre-1913 price indexes are taken from the Federal Reserve Bank of Minneapolis. 
a

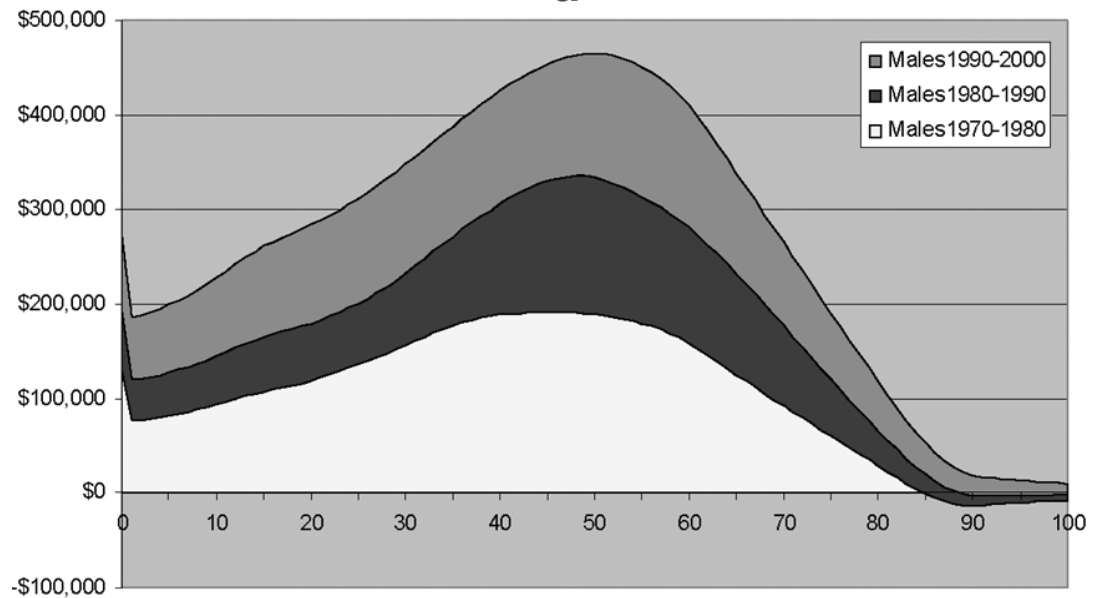

b

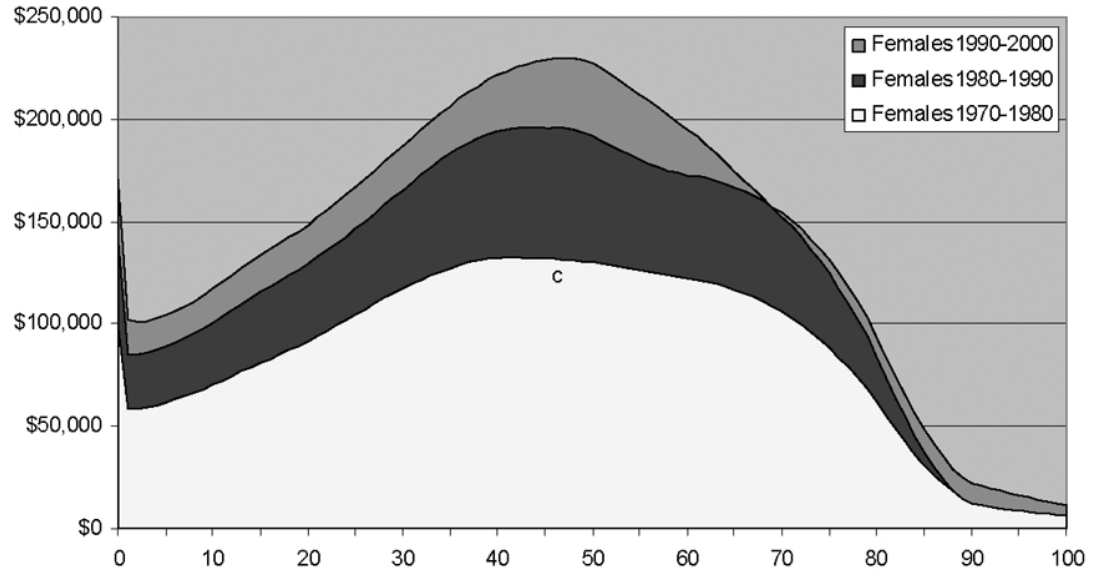

FIG. 6.-Gains from increased longevity, 1970-2000: $a$, males; $b$, females

Table 4 reports the social value of these advances, using (18) to aggregate over end-of-century and expected future populations. ${ }^{26}$ The numbers are huge because the relevant populations are large. For men, mortality reductions between 1970 and 1980 were worth $\$ 27$ trillion. Progress slowed after 1980, but even so the cumulative gains for men total $\$ 61$ trillion. Women gained "only" $\$ 34$ trillion because of stalled

${ }^{26}$ Equation (2) requires an estimate of future birth cohorts. We use the discounted value (at 3.5 percent) of projected births, as estimated by the Bureau of the Census (http://www.census.gov/ipc/www/usinterimproj/). In using this discount rate, we ignore anticipated economic growth, which would make our estimates larger. 


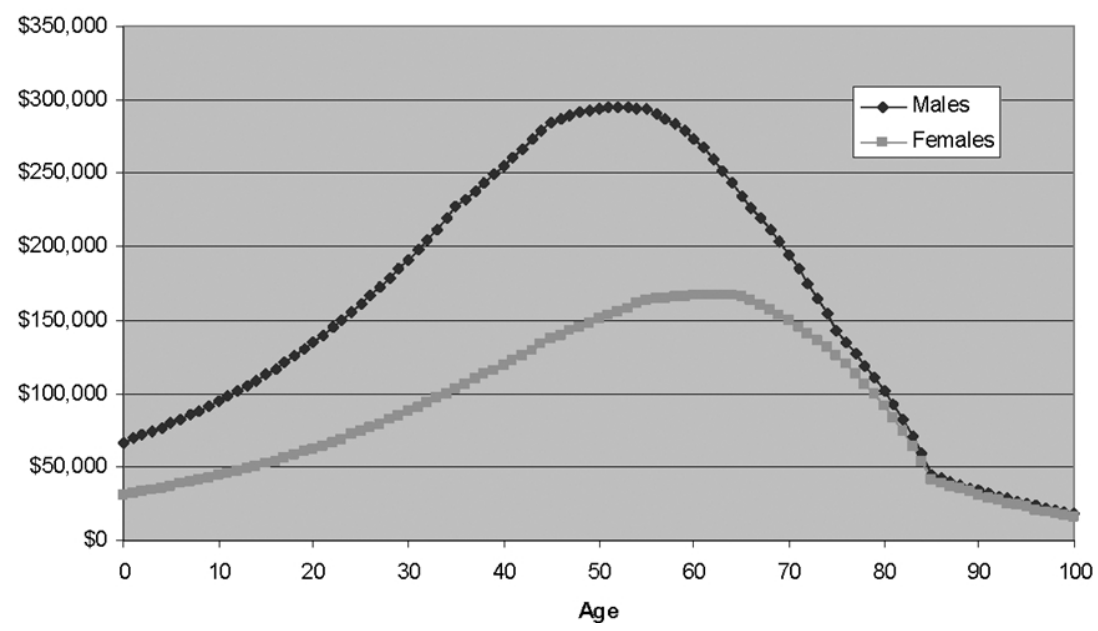

FIG. 7.-Gains from reductions in heart disease, 1970-2000

TABLE 4

Economic Gains from Reductions in Mortality, 1970-2000

(Billions of 2004 Dollars)

\begin{tabular}{lcccc}
\hline \hline & $1970-80$ & $1980-90$ & $1990-2000$ & $1970-2000$ \\
\hline Males & $\$ 26,699$ & $\$ 15,471$ & $\$ 19,153$ & $\$ 61,323$ \\
Females & $\$ 20,515$ & $\$ 9,067$ & $\$ 4,440$ & $\$ 34,022$ \\
Total & $\$ 47,214$ & $\$ 24,538$ & $\$ 23,593$ & $\$ 95,345$ \\
\hline
\end{tabular}

Note.-Aggregate gains were calculated using eq. (18) and year 2000 U.S. population by age. Population at birth includes census-predicted future birth cohorts discounted at 3.5 percent.

progress after 1980. When men's and women's gains are combined, reductions in mortality after 1970 had an end-of-century value of $\$ 95$ trillion, or a flow of about $\$ 3.2$ trillion per year. Separate calculations show that about two-thirds ( $\$ 64$ trillion) of this accrued to persons alive in 2000 , and one-third will be enjoyed by future birth cohorts.

\section{Net Gains: Accounting for Costs of Improving Health}

Health improvements are worthwhile if their value offsets additional costs, and we have counted only the value side of the ledger. Some costs take the form of changes in consumption or behavior, such as reductions in smoking or increased exercise in light of new information about health consequences. For example, suppose that the post-1970 decline in mortality among middle-aged men was entirely due to reduced smoking, caused by new knowledge that smoking promotes heart disease and other ailments. As smoking evidently provides enjoyment, the benefits 
of improved health came at a cost, and our estimates overstate net gains. In this case the usual welfare analysis indicates that net gains are about half the value of improved health.$^{27}$ Similar arguments apply to exercise, moderate drinking, and other choices that may have improved health.

Other (flow) costs are those associated with implementing new procedures and treatments, or simply greater consumption of existing services. These costs can either rise or fall as a consequence of technical advances, depending on the nature of the advance and the nature of demand for medical services. To incorporate them, assume that health expenditures at age $t, k(t)$, provide no direct utility beyond that necessary for maintaining health. An advance may improve longevity and quality of life while also changing costs. Willingness to pay is an extension of (15):

$$
\begin{aligned}
V_{\alpha}(a)= & \int_{a}^{\infty}\left[y^{F}(t)-k(t)+c^{F}(t) \Phi(z(t))\right]\left[S_{\alpha}(t, a)+S_{k}(t, a) k_{\alpha}(t)\right] d t \\
& -\int_{a}^{\infty} k_{\alpha}(t) S(t, a) d t \\
& +\int_{a}^{\infty} \frac{H_{\alpha}^{\prime}(t)+H_{k}^{\prime}(t) k_{\alpha}(t)}{H(t)} c^{F}(t)[1+\Phi(z(t))] S(t, a) d t .
\end{aligned}
$$

In (21) $k_{\alpha}(t)$ is the change in health spending at age $t$. If $k(t)$ is chosen efficiently, then terms involving $k_{\alpha}(t)$ vanish because the net return to a marginal increase in expenditure is zero. Then the balance of benefits and costs is surely positive and (21) is equivalent to (15). But third-party payers for medical services can distort these decisions, so the benefits of medical advances can be smaller than the costs of supplying them. This can be important on certain margins, as when large medical costs are incurred very near the end of life, allegedly to little benefit.

Our empirical analogue of (21) compares the value of increased longevity to changes in health expenditures. We use data on individuals' expenditures from the Medical Expenditure Surveys, collected in 1977, 1987, and then as a panel starting in 1996. As is typical with survey data, survey-predicted medical spending underestimates actual national expenditure for medical services. So we use the age profile of relative spending from the survey data to allocate national medical expenditures. This yields estimates of aggregate health care spending by age and gender from 1970 to 2000.

\footnotetext{
${ }^{27}$ Let $h$ be the previously unknown health cost per cigarette and $Q$ be quantity smoked. Then the gain in health is $h \Delta Q$ and the lost value of smoking is . $h h \Delta Q$. If consumers knew that smoking was harmful but had underestimated the harm, the forgone benefits of smoking are less than half the value of new health.
} 
TABLE 5

U.S. Health Expenditures, 1970-2000

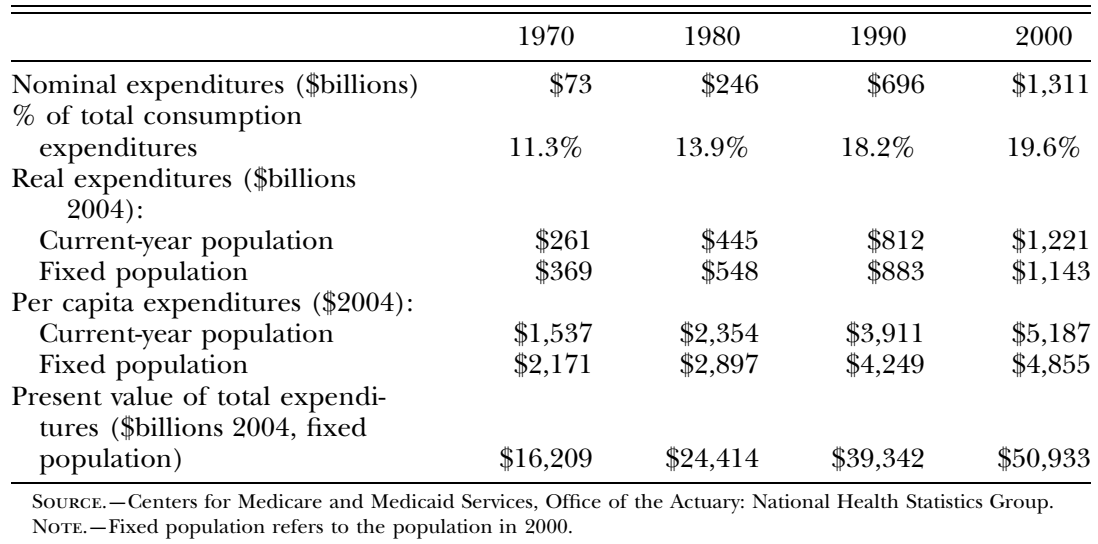

TABLE 6

Estimated Gains Net of the Increase in Health Expenditures, 1970-2000

\begin{tabular}{|c|c|c|c|c|}
\hline & $1970-80$ & $1980-90$ & $1990-2000$ & $1970-2000$ \\
\hline Gross gains (from table 4 ) & $\$ 47,214$ & $\$ 24,538$ & $\$ 23,593$ & $\$ 95,345$ \\
\hline Increase in expenditures & $\$ 8,206$ & $\$ 14,928$ & $\$ 11,591$ & $\$ 34,725$ \\
\hline $\begin{array}{l}\text { Gains net of expenditure } \\
\text { growth }\end{array}$ & $\$ 39,008$ & $\$ 9,611$ & $\$ 12,001$ & $\$ 60,620$ \\
\hline $\begin{array}{l}\text { Expenditure increase as a per- } \\
\text { centage of gains }\end{array}$ & $17.4 \%$ & $60.8 \%$ & $49.1 \%$ & $36.4 \%$ \\
\hline
\end{tabular}

Table 5 shows that medical spending grew from 11.3 percent of total consumption in 1970 to 19.6 percent in 2000 . When we calculate the present value of aggregate medical expenditures using 2000 population weights and survival probabilities, and assume that the same level of expenditure applies to future years and birth cohorts, the capital value of medical spending grew from $\$ 16.2$ trillion in 1970 to over $\$ 50$ trillion by 2000 .

Table 6 calculates net social gains from increased longevity. Note that our allocation of costs is only a rough analogue of (21), where $k_{\alpha}(t)$ represents the change in expenditures that are the direct consequence of implementing a new technology. We actually measure the value of increased longevity and changes in medical expenditures from all sources. This may cause either an overestimate or an underestimate of the social value of health improvements, for several reasons. First, changes in spending include expenditures that raise the quality of life, which we ignore. Second, current expenditures may yield future benefits, leading to an underestimate of net gains, or benefits we observe may be the outcome of past events, yielding an overestimate. Finally, 
TABLE 7

Economic Gains from Reductions in Mortality Net of Increased Health Care EXPENDitURe, By AGE AND GENDER, 1970-2000

\begin{tabular}{|c|c|c|c|c|c|c|}
\hline & Population & $1970-80$ & $1980-90$ & $1990-2000$ & $1970-2000$ & $\overline{\text { Cost/Value }}$ \\
\hline & \multicolumn{6}{|c|}{ Males } \\
\hline Birth & 72,134 & $\$ 119,958$ & $\$ 38,551$ & $\$ 61,967$ & $\$ 220,477$ & $19.2 \%$ \\
\hline $1-4$ & 7,938 & $\$ 68,373$ & $\$ 20,716$ & $\$ 49,657$ & $\$ 138,746$ & $26.9 \%$ \\
\hline $5-14$ & 19,681 & $\$ 81,703$ & $\$ 23,746$ & $\$ 60,995$ & $\$ 166,444$ & $26.1 \%$ \\
\hline $15-24$ & 18,618 & $\$ 105,116$ & $\$ 28,576$ & $\$ 78,704$ & $\$ 212,396$ & $24.7 \%$ \\
\hline $25-34$ & 20,191 & $\$ 139,412$ & $\$ 39,890$ & $\$ 86,580$ & $\$ 265,882$ & $23.0 \%$ \\
\hline $35-44$ & 21,569 & $\$ 167,199$ & $\$ 73,290$ & $\$ 87,865$ & $\$ 328,354$ & $21.7 \%$ \\
\hline $45-54$ & 15,836 & $\$ 166,351$ & $\$ 97,230$ & $\$ 95,943$ & $\$ 359,524$ & $22.0 \%$ \\
\hline $55-64$ & 10,166 & $\$ 133,497$ & $\$ 78,043$ & $\$ 94,456$ & $\$ 305,996$ & $25.8 \%$ \\
\hline $65-74$ & 8,325 & $\$ 69,395$ & $\$ 46,002$ & $\$ 59,350$ & $\$ 174,747$ & $36.5 \%$ \\
\hline $75-84$ & 4,486 & $\$ 16,138$ & $\$ 11,866$ & $\$ 32,473$ & $\$ 60,477$ & $55.9 \%$ \\
\hline \multirow[t]{2}{*}{$85+$} & 1,070 & $-\$ 21,094$ & $-\$ 5,191$ & $\$ 10,989$ & $-\$ 15,296$ & $147.7 \%$ \\
\hline & \multicolumn{6}{|c|}{ Females } \\
\hline Birth & 68,773 & $\$ 83,703$ & $\$ 14,249$ & $\$ 4,743$ & $\$ 102,695$ & $39.8 \%$ \\
\hline $1-4$ & 7,578 & $\$ 43,537$ & $-\$ 1,779$ & $-\$ 7,009$ & $\$ 34,749$ & $65.8 \%$ \\
\hline $5-14$ & 18,741 & $\$ 51,176$ & $-\$ 2,832$ & $-\$ 9,736$ & $\$ 38,608$ & $66.7 \%$ \\
\hline $15-24$ & 17,604 & $\$ 68,355$ & $-\$ 2,117$ & $-\$ 12,086$ & $\$ 54,153$ & $63.2 \%$ \\
\hline $25-34$ & 20,177 & $\$ 88,985$ & $\$ 2,131$ & $-\$ 14,513$ & $\$ 76,603$ & $58.8 \%$ \\
\hline $35-44$ & 21,824 & $\$ 98,440$ & $\$ 7,395$ & $-\$ 15,017$ & $\$ 90,818$ & $58.5 \%$ \\
\hline $45-54$ & 16,533 & $\$ 90,914$ & $\$ 1,438$ & $-\$ 13,128$ & $\$ 79,224$ & $65.0 \%$ \\
\hline $55-64$ & 11,195 & $\$ 75,543$ & $-\$ 13,315$ & $-\$ 27,842$ & $\$ 34,386$ & $82.5 \%$ \\
\hline $65-74$ & 10,345 & $\$ 54,837$ & $-\$ 17,060$ & $-\$ 51,047$ & $-\$ 13,269$ & $108.6 \%$ \\
\hline $75-84$ & 6,944 & $\$ 20,825$ & $-\$ 24,405$ & $-\$ 54,526$ & $-\$ 58,107$ & $163.5 \%$ \\
\hline $85+$ & 2,692 & $-\$ 17,106$ & $-\$ 34,698$ & $-\$ 46,378$ & $-\$ 98,182$ & $574.4 \%$ \\
\hline
\end{tabular}

SourcE. - Values by age underlying table 4 and imputations of health care spending by age and gender, as described in the text.

some observed gains may be due to things unrelated to medical spending-cleaner air or water, for example. We do not count the costs of these things.

With these caveats, we estimate that increased longevity after 1970 yielded a "gross" social value of $\$ 95$ trillion and the capitalized value of medical expenditures grew by $\$ 34$ trillion, for a net gain of $\$ 61$ trillion. Two-thirds of this "occurred" in the 1970s, when both gross benefits were highest and additional costs were lowest. Overall, rising medical expenditures absorb only 36 percent of the value of increased longevity.

While overall gains exceed costs, many critiques of the efficacy of rising medical expenditures focus on marginal decisions to expend resources when benefits are smaller than costs (e.g., Fuchs 1972; Meltzer 2003), especially on life-extending procedures for persons near death. ${ }^{28}$ Table 7 shows how average net gains vary with age. For men, net gains are positive overall and in each subperiod for all but the oldest $(85+)$

${ }^{28}$ For example, over a quarter of all Medicare expenditures are incurred in the last year of life, a proportion that has remained stable since the 1970s. See Hogan et al. (2001). 
age category. Incremental costs as a proportion of gross benefits are fairly constant until old age, when the cost share rises sharply. The cost share is uniformly larger for women, for whom we estimate negative average net benefits above age 65: the life-years they gained were worth less than their incremental health spending. In the 1990s we estimate net losses for women of all ages except infants, and deficits rise sharply with age. Though these deficits may surely be offset by uncounted improvements in the quality of life, they provide a cautionary tale that even large values may be swamped by increased costs.

\section{What's on the Table? Prospective Gains from Medical Progress}

We now turn to estimates of what can be gained from future progress against particular diseases. We make no attempt to deduct prospective costs, so our estimates should be interpreted as the value of life-years that could be gained from a given reduction in mortality. This value must be large enough to cover the costs of developing and implementing new methods that would save lives. Our benchmark is a 10 percent reduction in mortality from a disease.

Figure 8 shows individual values resulting from a permanent reduction in mortality from five major causes. The largest values are for cardiovascular diseases, which peak at nearly $\$ 35,000$ for men (fig. $8 a$ ) and $\$ 28,000$ for women (fig. $8 b$ ). The value of progress against cancer is nearly as large, with a noteworthy 20 -year earlier peak for women that reflects the incidence of breast cancer. Progress against infectious diseases-of which mortality from AIDS accounts for about a third-has a far lower value because of lower incidence, and it peaks early, reflecting the typical age of onset.

To get the current social values of potential progress, we aggregate over the age distribution of the 2000 U.S. population and future birth cohorts, as in (18). These are shown in table 8. A 10 percent reduction in all causes of mortality would have a present social value of $\$ 18.5$ trillion. About 30 percent of this ( $\$ 5.7$ trillion) is due to potential progress against cardiovascular diseases. Similar progress against cancer would be worth $\$ 4.7$ trillion, with roughly equal benefits for men and women. A 10 percent reduction in mortality from infectious diseases, including AIDS, has roughly the same value for men ( $\$ 500$ billion) that progress against breast cancer would have for women ( $\$ 444$ billion). For women, mortality-reducing progress against heart disease is four times more valuable than equivalent progress against breast cancer.

To put these values in perspective, total federal support for health research in the United States for fiscal 2005 was about $\$ 28$ billion. If we capitalize this flow over the indefinite future at 3 percent interest, it is roughly equal to the $\$ 1$ trillion value of a 1 percent reduction in 
a

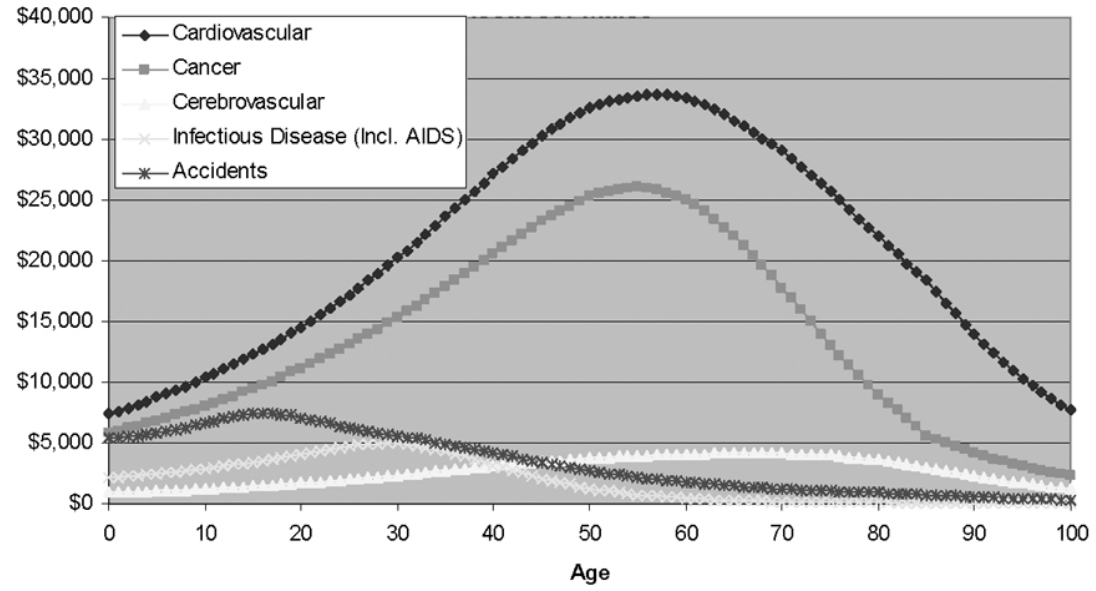

b

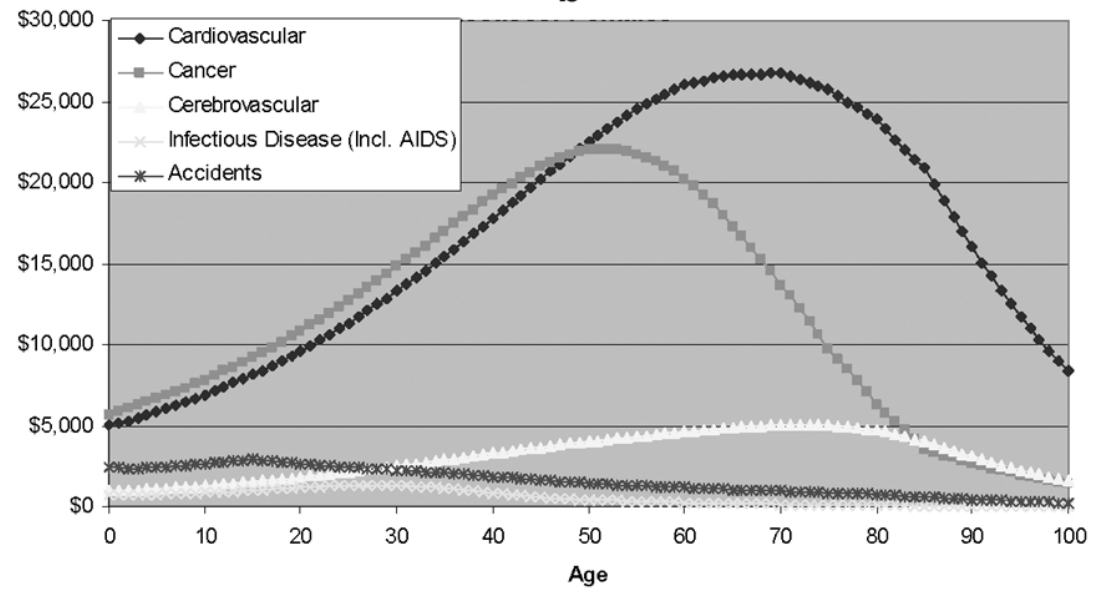

FIG. 8.-Prospective value of a 10 percent reduction in mortality from selected diseases: $a$, males; $b$, females.

mortality from cancer and cardiovascular disease. Even if we offset these gains by substantial increases in the cost of the treatments required to implement potential new technologies, potential net gains appear large.

Complementarity and Increasing Returns

Our earlier discussion emphasized the importance of complementarity as a source of increasing returns in the value of health. Columns 4 and 
TABLE 8

Current Value of a 10 Percent Reduction in Mortality from Major Diseases (Billions of 2004 Dollars)

\begin{tabular}{|c|c|c|c|c|c|}
\hline \multirow[b]{2}{*}{ Major Cause of Death } & \multirow[b]{2}{*}{$\begin{array}{l}\text { MaLes } \\
\text { (1) }\end{array}$} & \multirow[b]{2}{*}{$\begin{array}{l}\text { Females } \\
(2)\end{array}$} & \multirow[b]{2}{*}{$\begin{array}{c}\text { Total } \\
(3)\end{array}$} & \multicolumn{2}{|c|}{$\begin{array}{l}\text { COMPLEMENTAR- } \\
\text { ITY EFFECT }\end{array}$} \\
\hline & & & & $\begin{array}{l}\text { Value } \\
\text { (4) }\end{array}$ & $\begin{array}{c}\text { Share } \\
(5)\end{array}$ \\
\hline All causes & $\$ 10,651$ & $\$ 7,885$ & $\$ 18,536$ & $\$ 3,278$ & .18 \\
\hline Cardiovascular diseases & $\$ 3,254$ & $\$ 2,471$ & $\$ 5,725$ & $\$ 1,288$ & .22 \\
\hline Heart disease & $\$ 2,676$ & $\$ 1,852$ & $\$ 4,529$ & $\$ 1,013$ & .22 \\
\hline Cerebrovascular diseases & $\$ 393$ & $\$ 460$ & $\$ 852$ & $\$ 194$ & .23 \\
\hline Malignant neoplasms & $\$ 2,415$ & $\$ 2,261$ & $\$ 4,675$ & $\$ 863$ & .18 \\
\hline Respiratory and intrathoracic & $\$ 847$ & $\$ 557$ & $\$ 1,404$ & $\$ 278$ & .20 \\
\hline Breast & $\$ 3$ & $\$ 444$ & $\$ 447$ & $\$ 51$ & .11 \\
\hline Genital and urinary & $\$ 301$ & $\$ 302$ & $\$ 603$ & $\$ 126$ & .21 \\
\hline Digestive organs & $\$ 575$ & $\$ 431$ & $\$ 1,006$ & $\$ 200$ & .20 \\
\hline All other infectious diseases & $\$ 500$ & $\$ 148$ & $\$ 649$ & $\$ 60$ & .09 \\
\hline Obstructive pulmonary disease & $\$ 343$ & $\$ 331$ & $\$ 674$ & $\$ 153$ & .23 \\
\hline Pneumonia and influenza & $\$ 214$ & $\$ 194$ & $\$ 408$ & $\$ 98$ & .24 \\
\hline Diabetes & $\$ 237$ & $\$ 249$ & $\$ 486$ & $\$ 91$ & .19 \\
\hline Liver disease and cirrhosis & $\$ 217$ & $\$ 102$ & $\$ 319$ & $\$ 46$ & .14 \\
\hline Accidents and adverse effects & $\$ 977$ & $\$ 421$ & $\$ 1,398$ & $\$ 133$ & .10 \\
\hline Motor vehicle accidents & $\$ 519$ & $\$ 247$ & $\$ 767$ & $\$ 62$ & .08 \\
\hline \multicolumn{6}{|l|}{ Homicide and legal } \\
\hline intervention & $\$ 324$ & $\$ 90$ & $\$ 415$ & $\$ 29$ & .07 \\
\hline Suicide & $\$ 411$ & $\$ 102$ & $\$ 513$ & $\$ 50$ & 10 \\
\hline
\end{tabular}

Note. - The social value of a 10 percent reduction in mortality from the indicated disease, calculated using eq. (18). Calculations use 2000 population values and census predictions of future birth cohorts, discounted at 3.5 percent.

5 of table 8 illustrate this effect by calculating the impact of 1970-2000 health progress on prospective values. The estimates show the increase in the current social value of future progress that is due to the decline in mortality between 1970 and 2000. Formally we calculate

$$
\Delta W_{\alpha}=\int_{a=0}^{\infty}\left\{N^{1}(a)\left[V_{\alpha}^{1}(a)-V_{\alpha}^{0}(a)\right]+V_{\alpha}^{0}(a)\left[N^{1}(a)-N^{0}(a)\right]\right\} d a .
$$

The social value of health complementarity has two components. The first is how much more today's population $\left(N^{1}\right)$ will pay for future progress when that value is based on current survival rates $\left(V_{\alpha}^{1}\right)$ than on past ones $\left(V_{\alpha}^{0}\right)$. The second reflects the fact that today's population $\left(N^{1}\right)$ is larger than if people had lived their lives under mortality rates from $1970\left(N^{0}\right)$.

We find that declining mortality between 1970 and 2000 raised the social value of future health progress by 18 percent, or by $\$ 3.3$ trillion for our benchmark case of a 10 percent reduction in death rates. Of this, $\$ 2.2$ trillion is due to increased willingness to pay for progress against heart disease and cancer. These estimates illustrate that the value of health progress will continue to rise simply because people are getting 


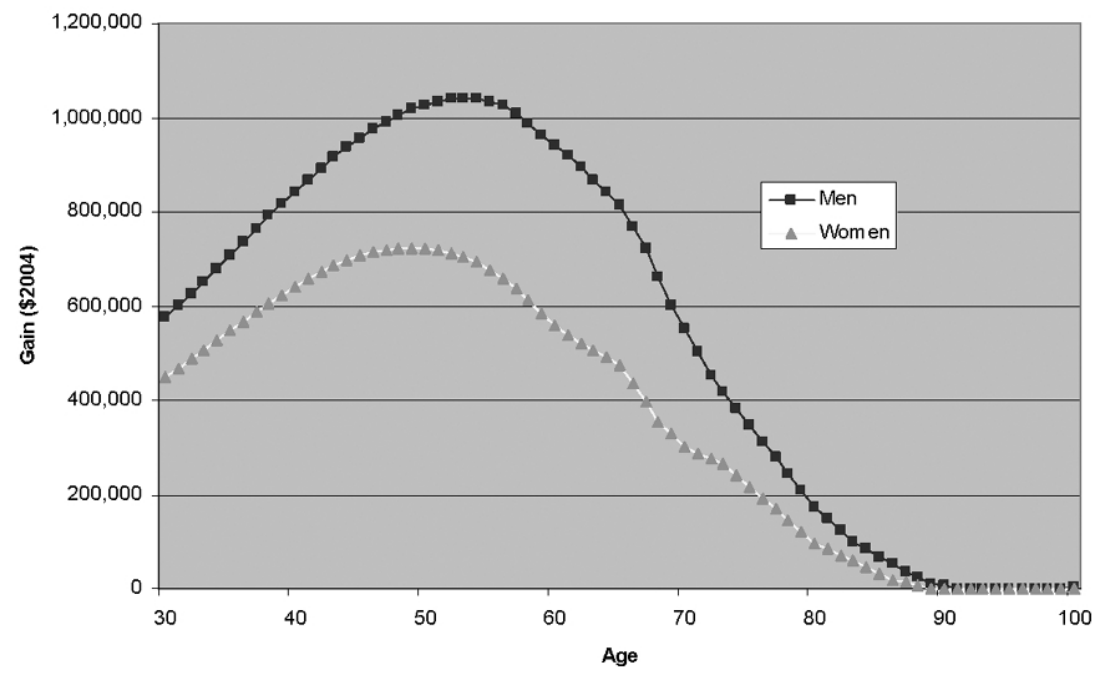

FIG. 9.-Estimated per capita gain from type $H$ health improvements, 1970-2000

healthier, even in the absence of growing productivity and incomes. Economic growth and income-elastic willingness to pay for health progress will only reinforce this effect.

\section{Changes in the Quality of Life}

Our calculations have valued changes in longevity, ignoring gains in the quality of life-what we called $H$. The reason is that changes in mortality are directly measurable, whereas changes in $H$ are not. Though we have no direct measure of these improvements, it seems obvious that they have occurred. We think that it is important to provide a ballpark estimate of how valuable they might be. Here is one approach.

Assume that advances in longevity and quality of life are related. Let $\lambda_{0}(t)$ and $\lambda_{1}(t)$ denote mortality rates in 1970 and 2000, respectively. Because mortality fell, assume that if $\lambda_{1}(t)=\lambda_{0}(t-k)$, then persons of age $t$ in 2000 are $k$ years "younger" than in 1970. We then assign $H^{\prime}(t) / H(t)=\ln H(t-k)-\ln H(t)$ from figure $2 a$ to calculate the second term of (15). Figure 9 shows the resulting value of post-1970 improvements in type $H$ health. Values reach $\$ 1$ million for men and $\$ 700,000$ for women in their late 40s. The estimates are large because people in middle age were much "younger" in 2000 than they were in 1970—a 55-year-old man in 2000 had the same death rate as a 49-year-old from 1970 - and our estimate of $H(t)$ is steeply declining. These estimates are roughly double the peak values from increased longevity shown in figure 
6 , suggesting that quality of life may be the more valuable dimension of recent health advances. ${ }^{29}$

\section{Conclusions}

We have developed a framework for valuing improvements in health based on willingness to pay and used this framework to estimate the value of past and prospective health advances. The resulting values are large. Reductions in mortality from 1970 to 2000 had an (uncounted) economic value to the 2000 U.S. population of about $\$ 3.2$ trillion per year. Cumulative longevity gains during the twentieth century were worth about $\$ 1.3$ million per person to the representative member of the 2000 U.S. population. Valued at the date they occurred, the production of longevity-related "health capital" would raise estimates of per capita output in the United States by from 10 to 50 percent, depending on the time period in question.

Prospectively, even modest progress against diseases such as cancer and heart disease would have enormous social values. A 1 percent reduction in mortality from cancer or heart disease would be worth nearly $\$ 500$ billion to current and future Americans. These estimates ignore the value of health advances to individuals in other countries, so they understate aggregate social values of possible innovations. They also ignore corresponding improvements in the quality of life-which evidence suggests may be even more valuable than gains in longevityand for these reasons as well they are likely to be conservative. We show that these values will increase in the future because of economic growth and, more interestingly, because health itself continues to improve.

Large as they are, these values may be offset by the costs of developing and implementing health improvements. Current public and private spending on health-related research is a tiny fraction of potential benefits, yet such investments may not be worthwhile if the costs of implementing new technologies are large. Social transfer programs and other third-party methods of financing health care can distort both utilization decisions and research, with the result that some health improvements are socially inefficient.

\section{References}

Arthur, W. B. 1981. "The Economics of Risks to Life." A.E.R. 71 (March): 5464.

${ }^{29}$ This method may overstate "quality" gains for several reasons. One is that we may have overstated the rate of decline in $H(t)$. But then our estimates of the value of increased longevity would be larger. Alternatively, mortality may decline for reasons unrelated to "health," e.g., a decline in accident rates. 
Banks, James, Richard Blundell, and Sarah Tanner. 1998. "Is There a RetirementSavings Puzzle?" A.E.R. 88 (September): 769-88.

Barsky, Robert B., F. Thomas Juster, Miles S. Kimball, and Matthew D. Shapiro. 1997. "Preference Parameters and Behavioral Heterogeneity: An Experimental Approach in the Health and Retirement Study." Q.J.E. 12 (May): 537-79.

Browning, Martin, Lars Peter Hansen, and James J. Heckman. 1999. "Micro Data and General Equilibrium Models." In Handbook of Macroeconomics, vol. 1A, edited by John B. Taylor and Michael Woodford. Amsterdam: Elsevier Sci.

Campbell, John Y., and N. Gregory Mankiw. 1989. "Consumption, Income, and Interest Rates: Reinterpreting the Time Series Evidence." In NBER Macroeconomics Annual 1989, edited by Olivier Jean Blanchard and Stanley Fischer. Cambridge, MA: MIT Press.

Conference Board of Canada. 2001. "The Future of Health Care in Canada, 2000 to 2020." Report, Conference Board Canada, Ottawa.

Cutler, David M., and Richardson, Elizabeth. 1997. "Measuring the Health of the U.S. Population.” Brookings Papers Econ. Activity: Microeconomics, pp. 21771.

Dockins, Chris, Kelly Maguire, Nathalie Simon, and Melonie Sullivan. 2004. "Value of Statistical Life Analysis and Environmental Policy: A White Paper." Manuscript, U.S. Environmental Protection Agency, National Center Environmental Econ., Washington, DC.

Ehrlich, Isaac, and Hiroyuki Chuma. 1990. "A Model of the Demand for Longevity and the Value of Life Extension.” J.P.E. 98 (August): 761-82.

Fernandez-Villaverde, Jesus, and Dirk Krueger. 2004. "Consumption over the Life Cycle: Some Facts from Consumer Expenditure Survey Data.” Paper presented at the 2004 meetings of the Society for Economic Dynamics.

Fuchs, Victor R. 1972. "Health Care and the United States Economic System: An Essay in Abnormal Physiology." Milbank Q. 50 (2): 211-37.

Hall, Robert E. 1988. "Intertemporal Substitution in Consumption." J.P.E. 96 (April): 339-57.

Hall, Robert E., and Chad Jones. 2005. "The Value of Life and the Rise in Health Spending." Working paper, Stanford Univ.

Hansen, Lars Peter, and Kenneth J. Singleton. 1983. "Stochastic Consumption, Risk Aversion, and the Temporal Behavior of Asset Returns." J.P.E. 91 (April): 249-65.

Hogan, Christopher, June Lunney, Jon Gabel, and Joanne Lynn. 2001. "Medicare Beneficiaries' Costs of Care in the Last Year of Life." Health Affairs 20 (July): 188-95.

Jones, Matthew T., and Maurice Obstfeld. 2001. "Saving, Investment, and Gold: A Reassessment of Historical Current Account Data." In Money, Capital Mobility, and Trade: Essays in Honor of Robert A. Mundell, edited by Guillermo A. Calvo, Rudiger Dornbusch, and Maurice Obstfeld. Cambridge, MA: MIT Press.

Lichtenberg, Frank R. 2001. "Are the Benefits of Newer Drugs Worth Their Cost? Evidence from the 1996 MEPS." Health Affairs 20 (September/October): 241-51.

Meltzer, David. 2003. "Can Medical Cost-Effectiveness Analysis Identify the Value of Research?" In Measuring the Gains from Medical Research: An Economic Approach, edited by Kevin M. Murphy and Robert H. Topel. Chicago: Univ. Chicago Press.

Miller, T. R., C. Calhoun, and W. B. Arthur. 1990. "Utility Adjusted Impairment Years: A Low-Cost Approach to Morbidity Valuation.” Manuscript, Fed. Highway Admin., Washington, DC. 
Moore, Michael J., and W. Kip Viscusi. 1988. "The Quantity-Adjusted Value of Life." Econ. Inquiry 26 (July): 369-88.

Murphy, Kevin M., and Robert H. Topel. 2003. "The Economic Value of Medical Research." In Measuring the Gains from Medical Research: An Economic Approach, edited by Kevin M. Murphy and Robert H. Topel. Chicago: Univ. Chicago Press.

. 2005a. "Black-White Differences in the Economic Value of Improving Health." Perspectives Biology and Medicine 48 (suppl.; Winter): S176-S194.

_ 2005b. "The Value of Health and Longevity." Working Paper no. 11405 (June), NBER, Cambridge, MA.

Nordhaus, William D. 2003. "The Health of Nations: The Contribution of Improved Health to Living Standards." In Measuring the Gains from Medical Research: An Economic Approach, edited by Kevin M. Murphy and Robert H. Topel. Chicago: Univ. Chicago Press.

Rosen, Sherwin. 1988. "The Value of Changes in Life Expectancy." J. Risk and Uncertainty 1 (September): 285-304.

- 1994. "The Quantity and Quality of Life: A Conceptual Framework." In Valuing Health for Policy: An Economic Approach, edited by George Tolley, Donald Kenkel, and Robert Fabian. Chicago: Univ. Chicago Press (for NBER).

Thaler, Richard, and Sherwin Rosen. 1975. "The Value of Saving a Life: Evidence from the Labor Market." In Household Production and Consumption, edited by Nestor E. Terleckyj. New York: Columbia Univ. Press (for NBER).

Tolley, George, Donald Kenkel and Robert Fabian. 1994. "State of the Art Health Values." In Valuing Health for Policy: An Economic Approach, edited by George Tolley, Donald Kenkel, and Robert Fabian. Chicago: Univ. Chicago Press (for NBER).

Topel, Robert H., and Finis Welch. 1986. "Efficient Labor Contracts with Employment Risk." Rand J. Econ. 17 (Winter): 490-507.

U.S. Environmental Protection Agency, Science Advisory Board. 2000. "SAB Report from the Environmental Economics Advisory Committee on EPA's White Paper 'Valuing the Benefits of Fatal Cancer Risk Reduction.'” Report, Environmental Protection Agency, Sci. Advisory Bd., Washington, DC.

Usher, Daniel. 1973. "An Imputation to the Measure of Economic Growth for Changes in Life Expectancy." In The Measurement of Economic and Social Performance, edited by Milton Moss. New York: Columbia Univ. Press (for NBER).

Viscusi, W. Kip. 1993. "The Value of Risks to Life and Health." J. Econ. Literature 31 (December): 1912-46.

Viscusi, W. Kip, and Joseph E. Aldy. 2003. "The Value of a Statistical Life: A Critical Review of Market Estimates throughout the World." Manuscript, Brookings Joint Center Regulatory Studies, Washington, DC. 